\title{
Aerosol remote sensing over land: A comparison of satellite retrievals using different algorithms and instruments
}

\author{
A.A. Kokhanovsky ${ }^{\mathrm{a}, *}$, F.-M. Breon $^{\mathrm{b}}{ }^{\text {, A. } \text { Cacciari }^{\mathrm{c}}, \text { E. Carboni }^{\mathrm{d}}, \text { D. Diner }}{ }^{\mathrm{e}}$, \\ W. Di Nicolantonio ${ }^{c}$, R.G. Grainger ${ }^{\text {d }}$, W.M.F. Grey ${ }^{f}$, R. Höller ${ }^{g}$, K.-H. Lee ${ }^{\text {h }}$, Z. Li ${ }^{\text {h }}$, \\ P.R.J. North ${ }^{\mathrm{f}}$, A.M. Sayer ${ }^{\mathrm{d}}$, G.E. Thomas ${ }^{\mathrm{d}}$, W. von Hoyningen-Huene ${ }^{\mathrm{a}}$ \\ a Institute of Environmental Physics, O. Hahn Allee 1, D-28334 Bremen, Germany \\ ${ }^{\mathrm{b}}$ Laboratoire des Sciences du Climat et de l'Environnement, CEA/DSM/LSCE, 91191 Gif sur Yvette, France \\ ${ }^{\mathrm{c}}$ Carlo Gavazzi Space S.p.A., Bologna CNR-ISAC Institute of Atmospheric and Climatic Sciences, via P. Gobetti 101, 40129 Bologna, Italy \\ d Atmospheric, Oceanic and Planetary Physics, Clarendon Laboratory, Parks Road, Oxford OXI 3PU, UK \\ e JPL, California Institute of Technology, Mail Stop 169-237, 4800 Oak Grove Drive, Pasadena, CA 91109, USA \\ ${ }^{\mathrm{f}}$ Climate and Land Surface Systems Interaction Centre, School of the Environment and Society, Swansea University, \\ Singleton Park, Swansea, SA2 8PP, UK \\ ${ }^{\mathrm{g}}$ Federal Environmental Agency, Spittelauer Lände 5, 1090 Wien, Austria \\ ${ }^{\mathrm{h}}$ Earth System Science Interdisciplinary Center, University of Maryland (UMD), 2114 C Computer and Space Sciences Building,
} MD 20742, USA

Received 3 January 2007; accepted 26 February 2007

\begin{abstract}
An inter-comparison study of the aerosol optical thickness (AOT) at $0.55 \mu \mathrm{m}$ retrieved using different satellite instruments and algorithms based on the analysis of backscattered solar light is presented for a single scene over central Europe on October 13th, 2005. For the first time comparisons have been performed for as many as six instruments on multiple satellite platforms. Ten different algorithms are briefly discussed and inter-compared. It was found that on the scale of a single pixel there can be large differences in AOT retrieved over land using different retrieval techniques and instruments. However, these differences are not as pronounced for the average AOT over land. For instance, the average AOT at $0.55 \mu \mathrm{m}$ for the area $7-12 \mathrm{E}, 49-53 \mathrm{~N}$ was equal to 0.14 for MISR, NASA MODIS and POLDER algorithms. It is smaller by 0.01 for the ESA MERIS aerosol product and larger by 0.04 for the MERIS BAER algorithm. AOT as derived using AATSR gives on average larger values as compared to all other instruments, while SCIAMACHY retrievals underestimate the aerosol loading. These discrepancies are explained by uncertainties
\end{abstract}

Abbreviations: AATSR, Advanced Along Track Scanning Radiometer; AERONET, AErosol Robotic NETwork; AFVI, Aerosol Free Vegetation Index; AOT, Aerosol Optical Thickness; BAER, Bremen AErosol Retrieval; CNES, French Space Agency; CNR, Italian National Research Council; ECMWF, European Center for Medium range Weather Forecasting; ENVISAT, ENVIronmental SATellite of the European Space Agency; ESA, European Space Agency; IPCC, Intergovernmental Panel on Climate Change; ISAC, Institute of Atmospheric Sciences and Climate; JPL, Jet Propulsion Laboratory; MERIS, MEdium Resolution Imaging Spectrometer; MISR, Multi-angle Imaging SpectroRadiometer; MODIS, MODerate resolution Imaging Spectroradiometer; NASA, NAtional Space Administration; PARASOL, Polarization and Anisotropy of Reflectances for Atmospheric Sciences coupled with Observations from a Lidar; POLDER, POLarization and Directionality of the Earth's Reflectances; SCIAMACHY, SCanning Imaging Absorption spectroMeter for Atmospheric ChartograpHY; TOA, Top of Atmosphere.

* Corresponding author.

E-mail address: alexk@iup.physik.uni-bremen.de (A.A. Kokhanovsky). 
in a priori assumptions used in the different algorithms and differences in the sensor characteristics. Validation against AERONET shows that MERIS provides the most accurate AOT retrievals for this scene.

(C) 2007 Elsevier B.V. All rights reserved.

Keywords: Satellite remote sensing; Atmospheric optics; Aerosols

\section{Introduction}

Atmospheric aerosol forcing is one of the greatest uncertainties in our understanding of the climate system (IPCC, 2001). To address this issue, many scientists are using Earth observations from satellites because the information provided is both timely and global in coverage. Aerosol properties over land and ocean have mainly been retrieved using passive optical satellite techniques, but it is well known that this is a very complex task. This is because one must separate surface and atmospheric contributions to the observed signal at the satellite level. In a second step, the aerosol contribution has to be separated from the atmospheric signal (molecular and cloud scattering). Often the aerosol contribution is small compared to the surface scattering, particularly over bright desert surfaces and snow.

Several algorithms have been applied to satellite datasets to solve the inverse problem of separating the surface and atmospheric scattering contributions. For instance, MODIS retrievals of aerosol over land (Kaufman et al., 1997; Remer et al., 2005) are based on the correlation of reflectances in the visible and shortwave infrared (SWIR). In essence, the algorithm assumes that the influence of aerosols on the top-of-atmosphere (TOA) reflectance in the SWIR is negligible. Therefore, the ground surface reflectance can be found at these wavelengths, (e.g., at $2.1 \mu \mathrm{m}$ for MODIS) by only correcting for Rayleigh scattering and gaseous absorption in the atmosphere. One can then exploit the correlation between the SWIR ground reflectances with those in the visible channels where aerosol scattering is significant. The derived surface reflectance is used for constraining the aerosol retrievals. Another possibility is to use multi-angle observations of the same ground scene, as is done with MISR and AATSR (Diner et al., 2005; Grey et al., 2006a,b; North et al., 1999, 2002; Thomas et al., 2005). This makes it possible to accurately account for directional surface scattering in the retrieval procedure. Some studies use polarized light for aerosol retrieval, e.g., from POLDER, employing the fact that atmospheric scattering is much more polarized than surface reflection (Deuze et al., 2001). The BAERMERIS algorithm (von Hoyningen-Huene et al., 2003) is based on studies of TOA reflectances in the blue region, where most surface types are only weakly reflective and the scattering from the atmosphere contributes more to the observed signal.

However, these diverse algorithms and approaches do not always give consistent values of the aerosol properties for a given ground scene. The problem is further complicated by the fact that the information content of satellite measurements is underconstrained as far as aerosol measurements are concerned. It is not always possible to constrain the phase function and the single scattering albedo from measurements themselves. Therefore, a priori assumptions are used that are typically based on prescribed aerosol models. Depending on the aerosol properties employed, and on the performance of the algorithms and accuracy of the underlying assumptions, different values of aerosol optical thickness may be retrieved.

The aim of this paper is to quantify the differences between the aerosol optical thickness (AOT) retrieved using different satellite instruments and algorithms for a study region in Europe. Such a comparison provides also valuable information for users of AOT products derived from satellite data, such as environmental agencies, that deal with air quality issues (Höller et al., 2005). Good agreement between aerosol retrievals from different satellite datasets and algorithms enhances confidence in remotely sensed estimates of AOT, but there is not always consistency between the different aerosol estimates. For instance, three independent studies by Bellouin et al. (2005), Chung et al. (2005) and $\mathrm{Yu}$ et al. (2005) had widely different conclusions concerning the effects of anthropogenic aerosols on the Earth's radiation budget based on satellite-derived aerosol estimates. This is because the satellite data themselves have different information content with respect to the viewing angle, spectral channels, spatial and temporal resolution, and polarization. Moreover, different simplifying assumptions and algorithms applied to the same data source can also result in different estimates of aerosol properties. This inter- 
comparison study tests the performance of different algorithms and satellite datasets for a region where multiple, near-simultaneous retrieval results are available. For the first time as many as ten different satellite algorithms aimed to the retrieval of the aerosol optical thickness for six optical instruments currently operated in space are inter-compared.

\section{Retrieval techniques and used instruments}

\subsection{Instruments}

Currently, satellite-based AOT retrieval techniques are developed by different research teams. A range of algorithms has been designed because the satellite sensors have different characteristics in terms of temporal, spatial, polarization, angular and spectral information content. Although these retrieval algorithms are different they should ideally produce consistent values for the aerosol properties for a given scene. In this study, we consider AOT at $0.55 \mu \mathrm{m}$ retrieved using different satellite instruments and algorithms. Only retrievals over land are considered in this work. The characteristics of selected satellite instruments used in this study are shown in Table 1. MERIS, AATSR, and
SCIAMACHY are on ENVISAT, MISR and MODIS are installed on TERRA, and POLDER is onboard PARASOL. AATSR, MERIS, and SCIAMACHY can be compared directly because they measure at the same place and time, thus in theory retrievals of AOT should be consistent across these three instruments. Comparisons between AOT derived from instruments on board different platforms may differ because there is a time difference between the observations. For instance, TERRA flies by approximately $30 \mathrm{~min}$ later than ENVISAT, and PARASOL approximately 90 min after ENVISAT. Therefore, AOTs derived from MISR, MODIS, and especially POLDER may not be identical to those obtained from instruments on ENVISAT. In addition, POLDER derives only the fine fraction contribution and not the total AOT.

One problem arises due to different spatial resolutions of different instruments (see Table 1). MODIS performs measurements with the spatial resolution of $0.5 \times 0.5 \mathrm{~km}^{2}$ at $0.55 \mu \mathrm{m}$, which is somewhat larger than those of MERIS $\left(0.3 \times 0.3 \mathrm{~km}^{2}\right)$. MISR radiance data are acquired at $0.275 \times 0.275 \mathrm{~km}^{2}$ and $1.1 \times 1.1 \mathrm{~km}^{2}$, depending on channel, and aerosol products are derived at $17.6 \times 17.6 \mathrm{~km}^{2}$ resolution. AATSR has a resolution of $1 \times 1 \mathrm{~km}^{2}$ and POLDER has the spatial resolution

Table 1

The characteristics of selected satellite instruments

\begin{tabular}{|c|c|c|c|c|c|}
\hline Instrument & $\begin{array}{l}\text { Satellite/time of } \\
\text { measurement }\end{array}$ & $\begin{array}{l}\text { Swath } \\
(\mathrm{km})\end{array}$ & Channels & Spatial resolution & Multi-angle observation \\
\hline MERIS & $\begin{array}{l}\text { ENVISAT } \\
\text { 10:00 UTC }\end{array}$ & 1150 & $\begin{array}{l}15 \text { bands } \\
0.4-1.05 \mu \mathrm{m}(0.41,0.44,0.49,0.51,0.56 \\
0.62,0.665,0.681,0.705,0.754 \\
0.76,0.775,0.865,0.89,0.9 \mu \mathrm{m})\end{array}$ & $0.3 \times 0.3 \mathrm{~km}^{2}$ & No \\
\hline AATSR & $\begin{array}{l}\text { ENVISAT } \\
\text { 10:00 UTC }\end{array}$ & 512 & $\begin{array}{l}7 \text { bands } \\
0.55,0.66,0.87,1.6,3.7,10.85,12.0 \mu \mathrm{m}\end{array}$ & $1 \times 1 \mathrm{~km}^{2}$ & $\begin{array}{l}\text { Yes, } 2 \text { angles from the } \\
\text { ranges } 0-21.732 \text { and } \\
55.587-53.009 \text { degrees }\end{array}$ \\
\hline SCIAMACHY & $\begin{array}{l}\text { ENVISAT } \\
\text { 10:00 UTC }\end{array}$ & 916 & $\begin{array}{l}8000 \text { spectral points } \\
0.24-2.4 \mu \mathrm{m}\end{array}$ & $30 \times 60 \mathrm{~km}^{2}$ & No \\
\hline MISR & $\begin{array}{l}\text { TERRA } \\
\text { 10:32 UTC }\end{array}$ & 400 & $\begin{array}{l}4 \text { bands } \\
0.446,0.558,0.672,0.866 \mu \mathrm{m}\end{array}$ & $\begin{array}{l}0.25 \times 0.25 \mathrm{~km}^{2} \text { at nadir } \\
\text { and at } 0.672 \mu \mathrm{m} \\
1.1 \times 1.1 \mathrm{~km}^{2} \text { in the } \\
\text { remaining channels }\end{array}$ & $\begin{array}{l}\text { Yes, } 9 \text { angles } 0,26.1,45.6 \text {, } \\
60.0,70.5^{\circ}\end{array}$ \\
\hline MODIS & $\begin{array}{l}\text { TERRA } \\
\text { 10:32 UTC } \\
\text { AQUA } \\
\text { 13:30 UTC }\end{array}$ & 2300 & $\begin{array}{l}36 \text { bands } \\
0.4-14.4 \mu \mathrm{m} \\
(1): 0.659,0.865 \\
(2): 0.47,0.555,1.24,1.64,2.13 \\
(3): 0.412,0.443,0.488,0.531,0.551, \\
0.667,0.678,0.748,0.869,0.905,0.936, \\
0.94,1.375+\text { MWIR(6)/LWIR } \\
\text { (10) channels }\end{array}$ & $\begin{array}{l}\text { (1): } 0.25 \times 0.25 \mathrm{~km}^{2} \\
\text { (2): } 0.5 \times 0.5 \mathrm{~km}^{2} \\
\text { (3): } 1 \times 1 \mathrm{~km}^{2}\end{array}$ & No \\
\hline POLDER & $\begin{array}{l}\text { PARASOL } \\
13: 33 \text { UTC }\end{array}$ & 1700 & $\begin{array}{l}8 \text { bands } \\
0.443,0.490^{*}, 0.565,0.670^{*} \\
0.865^{*}, 0.763,0.765,0.91\end{array}$ & $5.3 \times 6.2 \mathrm{~km}^{2}$ & $\begin{array}{l}\text { Yes, channels marked with* } \\
\text { have a capability to measure } \\
\text { polarization }\end{array}$ \\
\hline
\end{tabular}


$5.3 \times 6.2 \mathrm{~km}^{2}$. The resolution of SCIAMACHY depends on the spectral band and also on the latitude. It is $30 \times 30 \mathrm{~km}^{2}$ for all cases studied in this work, which means that most of pixels are contaminated by clouds and AOT determination is not possible in many cases.
The case with a cloudless sky for a large area in central Europe as shown in Fig. 1 was selected for this study. This enables the minimization of algorithm disturbances by clouds. The time of acquisition of the instruments is given in Table 1.

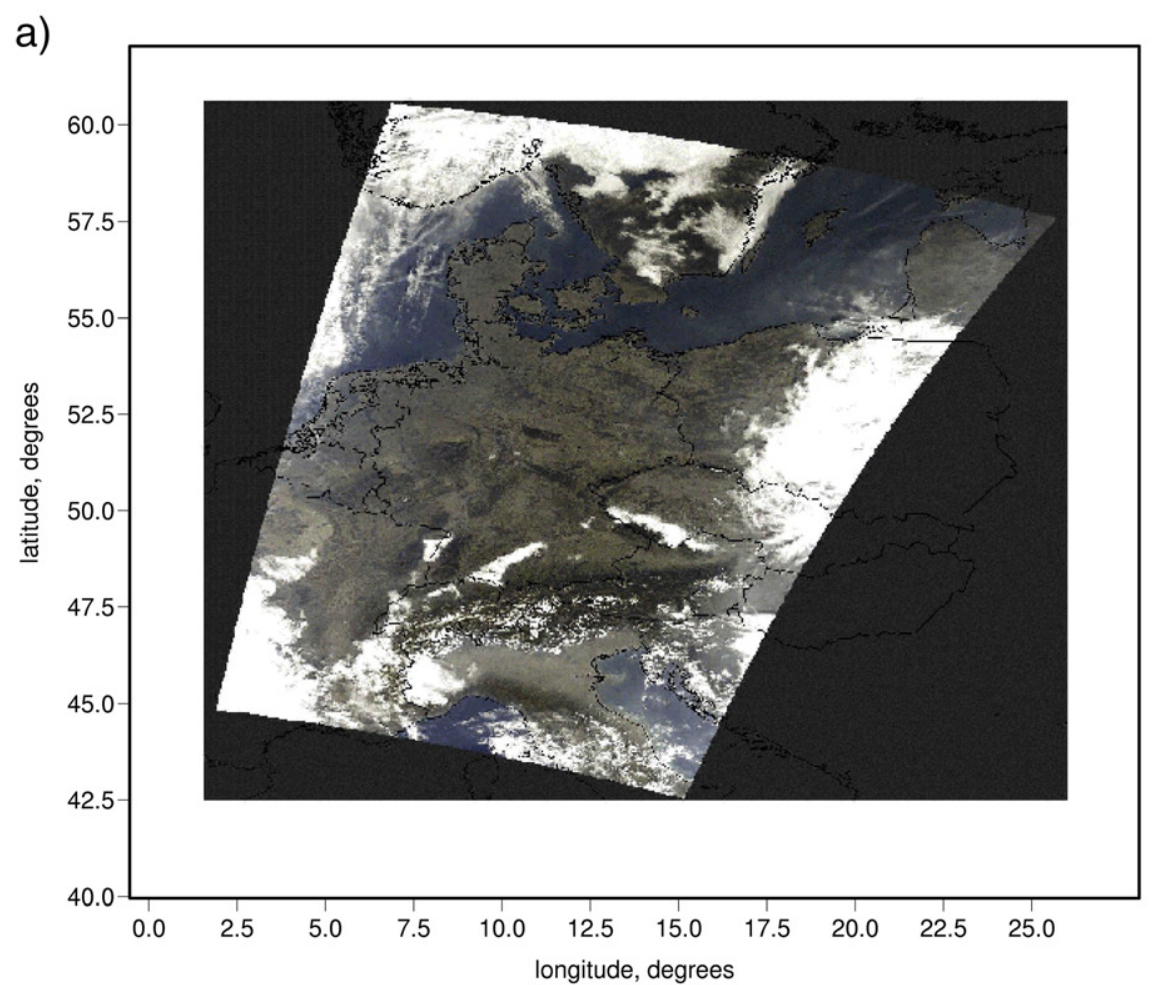

b)

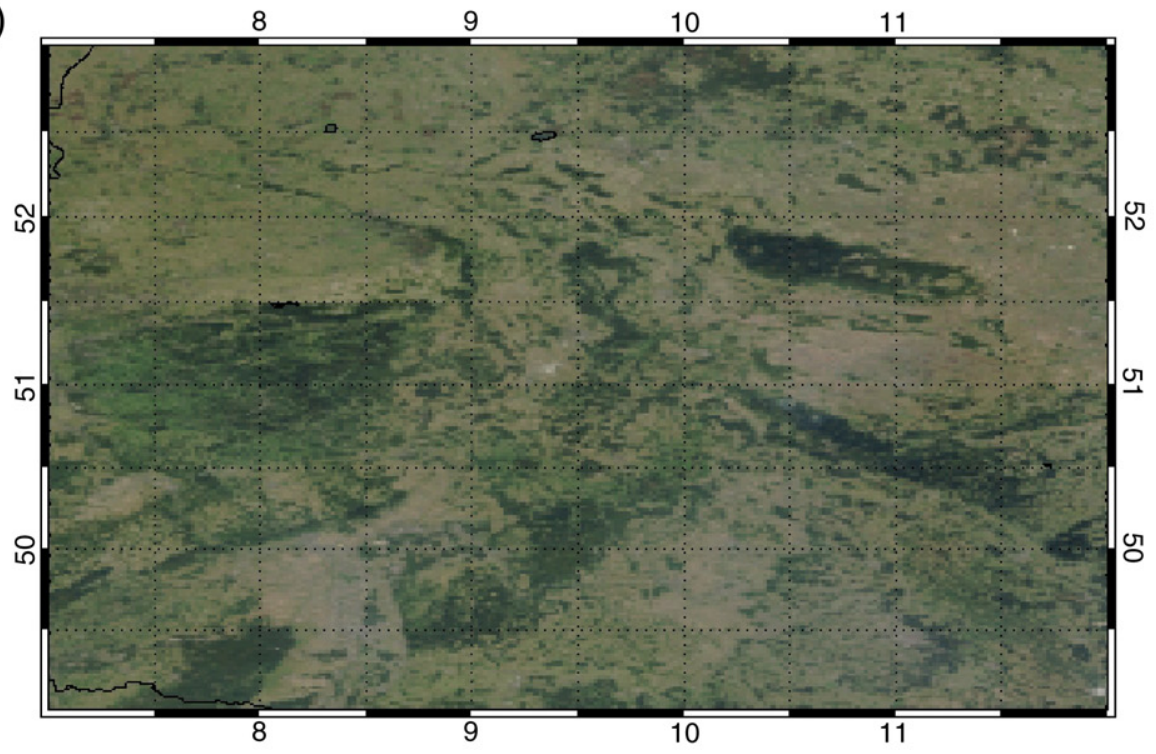

Fig. 1. a) The MERIS browse image of the selected scene (October 13, 2005, 10:00 UTC, orbit 18928 of ENVISAT). b) The browse image of the area $7-12 \mathrm{E}, 49-53 \mathrm{~N}$ used in the study. 


\subsection{Algorithms}

Because the characteristics of the satellite instruments differ, algorithms for aerosol retrieval have tended to be sensor-specific. For some instruments several algorithms have been developed. In this section an overview of the different algorithms is given. The characteristics of the datasets are summarized in Table 2.

\subsubsection{MERIS}

The results of two MERIS algorithms are analyzed in this study. The first algorithm was developed by Santer et al. $(1999,2000)$ specifically for aerosol retrievals from the MERIS instrument. The results of these retrievals are routinely distributed by ESA as a standard product. The ESA MERIS algorithm is based on the look-up-table (LUT) approach for selected aerosol size distributions with given refractive indices. It is assumed that particles have a spherical shape and the reflection from the ground is low. The algorithm fails in the cases of bright ground or non-spherical scatterers (e.g., desert dust aerosols). A detailed description is given in the MERIS Algorithm Theoretical Basis Document (ATBD) 2.15 (Santer et al., 2000). In practice, the ESA MERIS algorithm consists of two different routines, depending on the underlying surface. In both cases the retrieval relies on the knowledge of the underlying surface. Over water, two bands in the nearinfrared (NIR) $(0.779 \mu \mathrm{m}$ and $0.865 \mu \mathrm{m})$ and in the green $(0.51 \mu \mathrm{m})$ are used. Over land, two bands in the blue $(0.412 \mu \mathrm{m}$ and $0.443 \mu \mathrm{m})$ and one in the red $(0.665 \mu \mathrm{m})$ are used. Starting from the top-of-atmosphere (TOA) reflectance, first a gaseous correction is performed with ozone as auxiliary data. The surface pressure is determined from the oxygen absorption. Auxiliary data are the surface pressure at sea level and a digital elevation model. The apparent reflectance is then corrected for Rayleigh scattering. In the algorithm, aerosol parameters are retrieved based on comparisons of measured radiances with pre-calculated look-up tables for a representative set of aerosol models. Details on the aerosol models are given by Santer et al. (1999, 2000). The atmospherically resistant vegetation index (Kaufman et al., 1992) is then used to detect the dark dense vegetation pixels for land aerosol remote sensing. An auxiliary dataset, which is provided by POLDER, gives bi-directional reflectance versus time and location. The last module retrieves the aerosol optical thickness at $0.443 \mu \mathrm{m}$ and the Angström exponent. The MERIS standard aerosol product is also processed by the French company ACRI-ST, and supported by the ESA GSE project PROMOTE.

The second algorithm used for MERIS is BAER (Bremen AErosol Retrieval) which was developed by von Hoyningen-Huene et al. (2003). The algorithm is used by ESA for atmospheric correction of the MERIS land surface product. Although it is similar to that of Santer et al. (1999), it has special LUTs based on the experimentally measured phase function for central Europe. These LUTs were used in the BAER retrievals performed in this work. The main steps for the determination of the aerosol reflectance in the framework of BAER are:

- the determination of the spectral TOA reflectance for the selected bands using satellite data;

Table 2

Selected aerosol optical thickness retrieval algorithms

\begin{tabular}{|c|c|c|c|c|c|}
\hline$N$ & Instrument & Algorithm & Reference & $\begin{array}{l}\text { Spatial resolution of } \\
\text { reported AOT }\left(\mathrm{km}^{2}\right)\end{array}$ & Remarks \\
\hline 1. & MERIS & ESA & Santer et al. (1999) & $1 \times 1$ & Standard ESA product \\
\hline 2. & MERIS & BAER & $\begin{array}{l}\text { von Hoyningen-Huene } \\
\text { et al. (2003) }\end{array}$ & $1 \times 1$ & NDVI-based retrievals \\
\hline 3. & AATSR & AATSR-1 & Grey et al. (2006b) & $10 \times 10$ & Dual-view technique \\
\hline 4. & AATSR & AATSR-2 & $\begin{array}{l}\text { Thomas et al. } \\
\text { (in preparation) }\end{array}$ & $3 \times 3$ & Dual-view technique \\
\hline 5. & AATSR & AATSR-3 & $\begin{array}{l}\text { Thomas et al. } \\
\text { (in preparation) }\end{array}$ & $3 \times 3$ & Single-view technique \\
\hline 6. & SCIAMACHY & ASP & $\begin{array}{l}\text { Di Nicolantonio et al. } \\
\text { (submitted for publication) }\end{array}$ & $30 \times 30$ & $\begin{array}{l}\text { Single-view hyperspectral } \\
\text { measurements }\end{array}$ \\
\hline 7. & MISR & JPL & Diner et al. (2005) & $17.6 \times 17.6$ & Multiple view technique \\
\hline 8. & MODIS & NASA & Kaufman et al. (1997) & $10 \times 10$ & Spectral correlation technique \\
\hline 9. & MODIS & MBAER & Lee et al. (2005) & $1 \times 1$ & AFRI-based retrievals \\
\hline 10. & POLDER & CNES & Deuze et al. (2001) & $5.3 \times 6.2$ & $\begin{array}{l}\text { Multiple-angle polarized light measurements } \\
\text { ( } 16 \text { angles, up to } 50^{\circ} \text { cross-track and } \\
\text { up to } 60^{\circ} \text { along-track) }\end{array}$ \\
\hline
\end{tabular}


- the subtraction of the Rayleigh path reflectance for the geometric conditions of illumination and observation within the pixel;

- the estimation of the spectral surface reflectance for land and ocean surfaces by linear mixing of different basic spectra with the coefficient of mixing determined in the NDVI-type approach using wavelengths 0.665 and $0.865 \mu \mathrm{m}$;

- smoothing the retrieved spectral AOT, using an Ångström power law, by means of the iterative modification of the apparent surface reflectance.

The retrieved aerosol reflectance is then used to derive the AOT applying correspondent LUTs obtained by radiative transfer modeling.

\subsubsection{AATSR}

2.2.2.1. AATSR-1. North et al. (1999) developed a simple physical model of light scattering that is pertinent to the dual-angle sampling of the AATSR instrument and can be used to separate the surface bi-directional reflectance from the atmospheric aerosol properties without recourse to a priori information on the land surface properties (AATSR-1 algorithm in Table 2). Studies have shown that the angular variation of bidirectional reflectance at the different optical bands of the ATSR-2 and AATSR instruments are similar (e.g. Veefkind et al., 1998, 2000). North et al. (1999) adds to this work by considering the variation of the diffuse fraction of light with wavelength, where scattering by atmospheric aerosols tends to be greater at shorter wavelengths. This is important because the fraction of diffuse to direct radiation influences the anisotropy of light reflectance from the surface. Considering these contributions results is a physical model of spectral change with view angle (North et al., 1999). To constrain the inverse problem so that AOT is the only unknown atmospheric parameter, assumptions are made concerning the other aerosol optical properties (e.g. phase function and single scattering albedo). The algorithm uses pre-calculated lookup tables derived from the 6S (Second Simulation of the Satellite Signal in the Solar Spectrum) radiative transfer model of Vermote et al. (1997) to allow for rapid inversion. A numerical iteration is used to search through different atmospheric profiles to find the AOT that results in the optimal set of surface reflectances.

The retrieved properties include a set of eight surface bi-directional reflectance factors at four wavelengths and two angles, AOT at $0.55 \mu \mathrm{m}$ and an estimate of the tropospheric aerosol model that falls into one of five compositional categories including continental (predominantly composed of dust-like particles), urban, seasalts, biomass (smoke) and desert-dust aerosols.

\subsubsection{AATSR-2,3. The Oxford-RAL retrieval of} Aerosol and Cloud properties, known as ORAC (Thomas et al., 2005, in preparation; Poulsen et al., in preparation) is an optimal estimation (OE) scheme designed for retrievals from near-nadir satellite radiometers. ORAC is referred to as AATSR-2 in this paper for dual-view retrievals and as AATSR-3 for singleview (in nadir or forward observation mode) retrievals. The AATSR and SEVIRI aerosol data obtained with this ORAC algorithm, together with the ESA MERIS product, are supported by the ESA DUE Project GLOBAEROSOL (Carboni et al., 2006), and both individual and merged AOT data are available.

The aerosol algorithm currently retrieves aerosol optical depth at $0.55 \mu \mathrm{m}$, effective radius of aerosol particles and surface albedo. The algorithm uses the Levenberg-Marquardt method to fit the simulated radiance to the measurements, minimising a cost function based on OE techniques (Rodgers, 2000).

The forward model takes into account scattering and absorption by aerosol, gases and Rayleigh scattering. The radiative transfer equation is solved, at each wavelength, with DISORT (Stamnes et al., 1998), using 60 streams with the delta-M approximation (Wiscombe, 1977) stored in lookup tables (LUTs).

The atmosphere is modelled with 32 layers as described by the U.S. standard atmosphere model. Each layer is a mixture of molecules and aerosol and is characterized by a value of optical depth and single scattering albedo and phase function (expressed in terms of Legendre moments). Aerosol is placed only at height levels appropriate for the aerosol type. Aerosol optical properties are obtained using the Mie theory (Grainger et al., 2004). Every aerosol type considered is a combination of different aerosol components (from the OPAC database, Hess et al., 1998) and the mixing ratio is changed in order to obtain different effective radii.

Gas absorption optical depth for the local gases are obtained from MODTRAN (Moderate Resolution Transmittance code) v3.5 and convolved with the instrumental channel spectral shape.

An optimal estimation approach to the retrieval of parameters enables the extraction of information from all channels simultaneously. This method also allows characterization of the error in each parameter in each individual observation (or 'pixel') under the assumption that the aerosol observed is consistent with the modeled aerosol (i.e. reasonably plane-parallel in nature). A 
second diagnostic (the solution cost) indicates whether in fact this assumption is true. The OE framework also enables the use of any prior information on the pixel observed. In particular, a priori information on the surface albedo is used. The scheme uses surface reflectances based on the MODIS BRDF product (Jin et al., 2003) over land and a model based on Cox and Munk (1954) wave slope statistics over ocean. The surface albedo is retrieved by first assuming an albedo spectral shape for the $0.55,0.67,0.87$ and $1.6 \mu \mathrm{m}$ channels. The retrieval searches for the solution with the lowest cost by varying the albedo in the $0.55 \mu \mathrm{m}$ channel and keeping the respective ratios of all other channels to this channel constant.

The dual-view AATSR-2 aerosol retrieval is an extension of the scheme described above. Instead of using data from one viewing geometry it uses both forward and nadir measurements simultaneously, and retrieves a pair of surface albedo values instead of one. The treatment of aerosol is the same as in the singleview AATSR-3 algorithm. The AATSR-2 retrieval algorithm is only carried out on pixels where both forward and nadir data is not flagged as cloudcontaminated (using a ratio threshold test).

For both the AATSR-2 and AATSR-3 algorithms, a variable resolution is possible by averaging nearby data points. In this instance the retrieval was performed at $3 \times 3 \mathrm{~km}^{2}$ resolution in both cases, this 'superpixelling' of data decreasing the effective noise on the measurements by a factor of up to 3 for a completely cloud-free superpixel.

\subsubsection{SCIAMACHY}

Aerosol retrieval from SCIAMACHY data Processing (ASP) technique was developed at ISAC-CNR as reported in Di Nicolantonio et al. (2006). The algorithm retrieves AOT at $0.5 \mu \mathrm{m}$ together with a parameter (class) which defines a set of chemico-physical properties pertaining to suspended particles. SCIAMACHY Level 1B data (calibrated and geolocated radiance and solar irradiance) from nadir measurements both over ocean and land are used as input. The TOA reflectance is simulated with MODTRAN v.4 code. The selected wavelengths are $0.364,0.387,0.429,0.683,0.754$, and $0.775 \mu \mathrm{m}$. Additionally for reducing surface reflectance contribution to TOA signal, the last two wavelengths are employed only in case of oceanic pixels.

At specified wavelengths, measured TOA reflectance are carefully corrected taking into account that SCIAMACHY underestimates the reflectance in the UV and VIS range by 10 to $25 \%$ and by 10 to $20 \%$, respectively. Then corrected reflectances presenting values of the effective cloud coverage fraction, provided by FRESCO (Koelemeijer et al., 2001), lower than 0.05 are fitted with modeled reflectances. In this context, taking also into account the alternate limb-nadir sampling mode of SCIAMACHY and its pixel dimension, the number of observations useful for AOT determination is significantly reduced.

Simulated reflectances are calculated with the DOWNSTREAM radiative transfer code (Levoni et al., 2001) as a function of aerosol optical parameters such as single scattering albedo, phase function and AOT. These properties are derived by means of the Mie theory applied to both literature-derived and in-situ measured microphysical properties, thus realizing a set of aerosol optical properties related to eight aerosol classes. The global database of monthly Minimum Lambert-Equivalent Reflectivity, derived from 5 years of GOME observations, (Koelemeijer et al., 2003) is chosen to estimate the surface contribution to TOA reflectance. Finally, the couple formed by AOT and class, producing the best-fit between simulated and measured spectral TOA reflectance using the Levenberg-Marquardt method, represents the retrieved aerosol parameters.

\subsubsection{MISR}

The MISR retrieval technique uses measurements at 9 angles and 4 spectral bands to constrain the aerosol retrievals. The MISR algorithm makes use of a prescribed set of aerosol models considered to be representative of the types to be found over the globe, and determines for which models, and at what optical depth for each model, a set of acceptance criteria is satisfied. The models are bimodal or trimodal mixtures of fine mode aerosols of various size distributions and single scattering albedo, coarse mode aerosols, and nonspherical dust. Air mass factors ranging from 1 to 3 (owing to the view angle range from nadir to $70^{\circ}$ ) provide considerable sensitivity to aerosol optical depth, especially for thin haze. MISR's nine near-simultaneous views also cover a broad range of scattering angles, between about $60^{\circ}$ and $160^{\circ}$ in mid-latitudes. Over land, the principal problem is separating the surface and atmospheric contributions to the observed top-of-atmosphere radiances. MISR takes advantage of the increasing ratio of atmospheric to surface contributions to the top-of-atmosphere signal with increasing view zenith angle. The MISR algorithm models the shape of the surface bi-directional reflectance as a linear sum of angular empirical orthogonal functions derived directly from the image data, making use of spatial contrast and angular variation in the observed signal to separate the 
surface and atmospheric signals even in situations where bright, dusty aerosols overlay a bright, dusty surface (Martonchik et al., 2002; Diner et al., 2005). A constraint imposing spectral invariance in the angular shape of the surface directional reflectance is also employed in the retrievals (Diner et al., 2005). Globally, MISR optical depths have been validated against AERONET and other sun photometers over a wide variety of surface types (e.g., Martonchik et al., 2004; Abdou et al., 2004; Kahn et al., 2005).

\subsubsection{MODIS}

Two MODIS techniques are analyzed in this work. One is based on the NASA near IR-visible surface albedo correlation approach (Kaufman et al., 1997) and yet another is the modified BAER (MBAER) algorithm described by Lee et al. $(2005,2006)$.

Operational aerosol product of MODIS level 2 aerosol datasets (MOD04 L2; MODIS aerosol product, Version 4.1.3) obtained using the technique described by Kaufman et al. (1997) was collected from National Aeronautics and Space Administration (NASA) Distributed Active Archive Center (DAAC) (http://eosdata. gsfc.nasa.gov/). The retrieval is based on the fact that the aerosol contribution is low at $2.1 \mu \mathrm{m}$. This enables an accurate determination of the surface contribution at this wavelength. The information on the surface reflectance in the near-infrared is used to estimate the surface reflectance in the visible (Kaufman et al., 1997). The MOD04 data has various aerosol physical and optical parameters with $10 \times 10 \mathrm{~km}^{2}$ spatial resolution. The MODIS AOT $\tau_{\mathrm{a}}$ has been validated with ground-based sun photometer AOT by a spatio-temporal approach (Ichoku et al., 2002). It has been shown that the MODIS aerosol retrievals over land surface, except in coastal zones, are found within retrieval errors $\Delta \tau_{\mathrm{a}}= \pm 0.05 \pm$ $0.2 \tau_{\mathrm{a}}$ (Chu et al., 2002).

MBAER (Lee et al., 2005, 2006) uses a so-called Aerosol Free Vegetation Index (AFRI; Karnieli et al., 2001) coupled with LUTs constructed using SBDART code (Ricchiazzi et al., 1998) for $1 \mathrm{~km}$ resolution MODIS AOT retrieval. The clouds and sun glint pixels are masked using the MODIS clear sky discriminating method (MOD35; Ackerman et al., 1998). The Rayleigh optical thickness is obtained (Buchholtz, 1995) from the surface pressure determined by the height of the ground for the pixel analyzed. The separation of surface reflectance from TOA reflectance over land involves the use of a linear mixing model of the spectral reflection of green vegetation and soil. The spectra used are given by von Hoyningen-Huene et al. (2003). This enables the estimation of the land surface reflectance for a given pixel. For the contribution of vegetation spectra, the aerosol free vegetation index (Karnieli et al., 2001) is used. Since this index can minimize aerosol effect, the vegetation fraction can be determined quite accurately. Surface reflectance determined by the linear mixing model tuned by the corrected aerosol free vegetation index is then used to determine AOT.

\subsubsection{POLDER}

POLDER (POLarization and Directionality of Earth Reflectances, Deschamps et al., 1994) performs multiangle measurements of the sunlight reflected by the Earth surface and atmosphere at eight spectral bands in the visible and near-infrared spectral domain $(0.443$ to $1.02 \mu \mathrm{m})$. The data used here were acquired by the third version of the instrument onboard the micro-satellite PARASOL, while the two previous versions were onboard ADEOS 1 and 2. Multidirectional and polarization measurements provide additional information to retrieve aerosol load in the atmosphere. Indeed, the reflectance from the surface shows little polarization while that of fine aerosol is highly polarized. As a consequence, the relative contribution of the aerosols to the top-of-the-atmosphere reflectance is much higher for the polarized component than that for the total component, which makes it easier to identify aerosol signatures than with the other instruments discussed here. On the other hand, coarse aerosols generate little polarized light so that the POLDER retrieval focuses on the fine fraction of the aerosols. Aerosol generated by pollution and biomass burning are mostly in the fine mode and are therefore well captured by the retrieval method (Deuze et al., 2001). On the other hand, dust is mostly in the coarse mode. The retrieval algorithm assumes spherical scatterers, which is valid for fine aerosols. The contribution from the surface to the polarized reflectance is based on a priori values (as a function of observation geometry and surface type) derived from a statistical analysis of POLDER data (Nadal and Bréon, 1999). The aerosol load and type is obtained through a classical LUT algorithm based on the multi-directional polarized reflectance measurements at 0.67 and $0.865 \mu \mathrm{m}$.

\section{Description of study site}

The study site as shown in Fig. 1a includes the cloudless ground scene in central Europe (mainly, Germany) on October 13, 2006 (10:00 UTC). The latitude range of performed inter-comparisons of different retrieval algorithms was from $49 \mathrm{~N}$ to $53 \mathrm{~N}$ 
and the longitude range was from $7 \mathrm{E}$ to $12 \mathrm{E}$. This fairly large area $\left(5^{\circ} \times 4^{\circ}\right)$ enables the better matching of measurements by different instruments. The surface is mostly covered by dense vegetation with some areas of bare soil (see Fig. 1b). The surface is not as bright as compared, e.g., to dry regions such as those in the southern Europe and Sahara. This makes aerosol retrievals less dependent on surface reflective characteristics (e.g., bi-directional reflection function).

The study area is surrounded by clouds. There is also some indication of small clouds in some parts of the study area which is, however, mostly cloud-free (see Fig. 1). The humidity was low (below $40 \%$ for most of area) and the boundary layer height was about $1 \mathrm{~km}$ as indicated by ECMWF analysis. The analysis of relevant meteorological data suggests that the situation was characterized by high pressure conditions with the average temperature of $14^{\circ} \mathrm{C}$ at $10: 00 \mathrm{UTC}$ and $17^{\circ} \mathrm{C}$ at 13:00 UTC.

Several AERONET (Holben et al., 1998) instruments operated at the time of satellite measurements. Their locations, time of measurements, and values of aerosol optical thickness at wavelengths $0.44,0.55$, and $0.67 \mu \mathrm{m}$ are given in Table 3. It follows from this table that the average AOT at $0.55 \mu \mathrm{m}$ for most instruments was close to 0.2 at October 13th, 2005 for the central Europe. It is interesting to see what is the correspondent AOT retrieved from backscattered light measurements. This is considered in the next section.

\section{Results of inter-comparisons}

\subsection{AATSR, MERIS, and SCIAMACHY onboard ENVISAT}

Since AATSR, MERIS, and SCIAMACHY are onboard the same platform, the retrieved AOTs were acquired at the same time (10:00 UTC; October 13, 2005). However, the instruments have different spatial resolutions. Therefore, the AATSR and MERIS pixels must be re-sampled to be compared with those of SCIAMACHY. This can be done only for the part of MERIS and AATSR pixels because SCIAMACHY measurements alternate between nadir and limb measurements and also because the swath of AATSR measurement is narrow $(512 \mathrm{~km})$ as compared to the swath of SCIAMACHY $(960 \mathrm{~km})$ and MERIS $(1150 \mathrm{~km})$ (see Table 1). However, we can still identify and collocate many MERIS, AATSR, and SCIAMACHY measurements of the same ground scene.

The difference in the MERIS, AATSR, and SCIAMACHY AOT for the spatially collocated measurement could be mainly due to following factors:

- the difference in a priori assumptions (e.g., shapes of particles, size distributions, refractive indices, spectral aerosol optical properties databases including spectral single scattering albedo, surface reflectance model, vertical columns of trace gases) in the different algorithms;

- horizontal inhomogeneity effects (e.g., AOT as retrieved from one value of the top-of-atmosphere SCIAMACHY reflectance must not be necessarily equal to the average AOT obtained from about 1800 reflectances of MERIS);

- instrumental effects (e.g., calibration differences between instruments);

- the different information content of the satellite instruments.

The possible range of differences in the retrievals due to different algorithms for the same instrument (AATSR) is demonstrated in Fig. 2. Fig. 2a serves for the illustration of work of the spatial matching

Table 3

The AERONET aerosol optical thickness at $0.44 \mu \mathrm{m}$ and $0.67 \mu \mathrm{m}$ obtained at several locations in Europe on September 13th, 2005(Bremen is not an official AERONET site)

\begin{tabular}{lllll}
\hline Station & Position & Time & $\tau(0.44 \mu \mathrm{m})$ & 0.15 \\
\hline Hamburg & $53.568 \mathrm{~N}, 9.973 \mathrm{E}$ & $09: 52$ & 0.21 & 0.11 \\
Helgoland & $54.178 \mathrm{~N}, 7.887 \mathrm{E}$ & $09: 45$ & 0.27 & 0.20 \\
Cabauw & $51.971 \mathrm{~N}, 4.927 \mathrm{E}$ & $09: 57$ & 0.25 & 0.19 \\
Den Haag & $52.110 \mathrm{~N}, 4.327 \mathrm{E}$ & $09: 44$ & 0.31 & 0.22 \\
Leipzig & $51.354 \mathrm{~N}, 12.435 \mathrm{E}$ & $10: 06$ & 0.24 & 0.17 \\
Mainz & $49.999 \mathrm{~N}, 8.300 \mathrm{E}$ & $09: 58$ & 0.42 & 0.16 \\
Karsruhe & $49.093 \mathrm{~N}, 8.428 \mathrm{E}$ & $09: 43$ & 0.31 & 0.13 \\
ISGDM_CNR & $45.437 \mathrm{~N}, 12.332 \mathrm{E}$ & $09: 59$ & 0.57 & 0.22 \\
Venice & $45.314 \mathrm{~N}, 12.508 \mathrm{E}$ & $09: 29$ & 0.47 & 0.41 \\
Bremen & $53.05 \mathrm{~N}, 8.78 \mathrm{E}$ & $10: 06$ & 0.35 & 0.31 \\
\hline
\end{tabular}

The value of aerosol optical thickness $\tau$ at $0.55 \mu \mathrm{m}$ was obtained using correspondent Ångström coefficients. 
a)

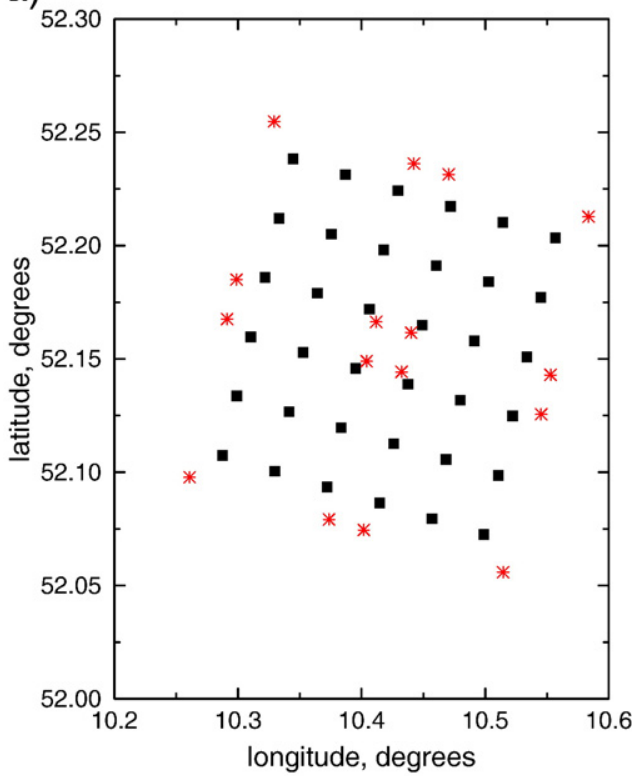

c)

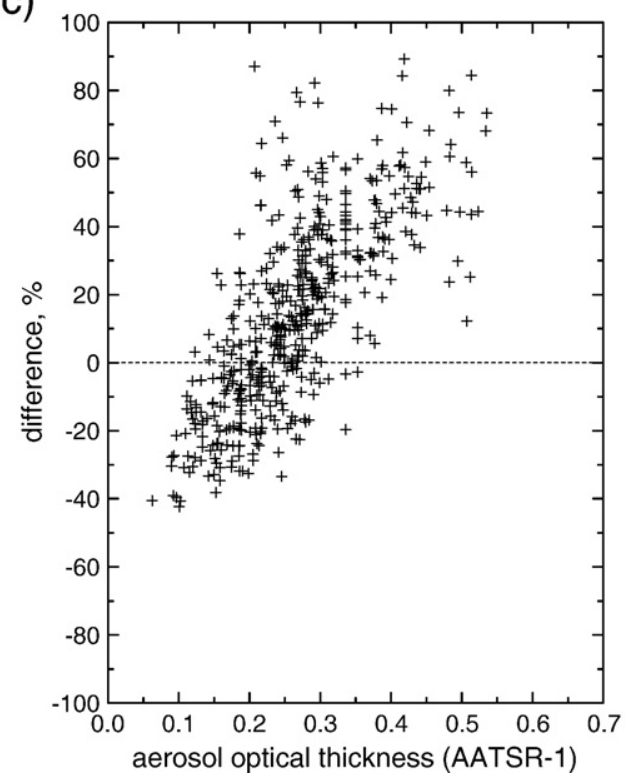

b)

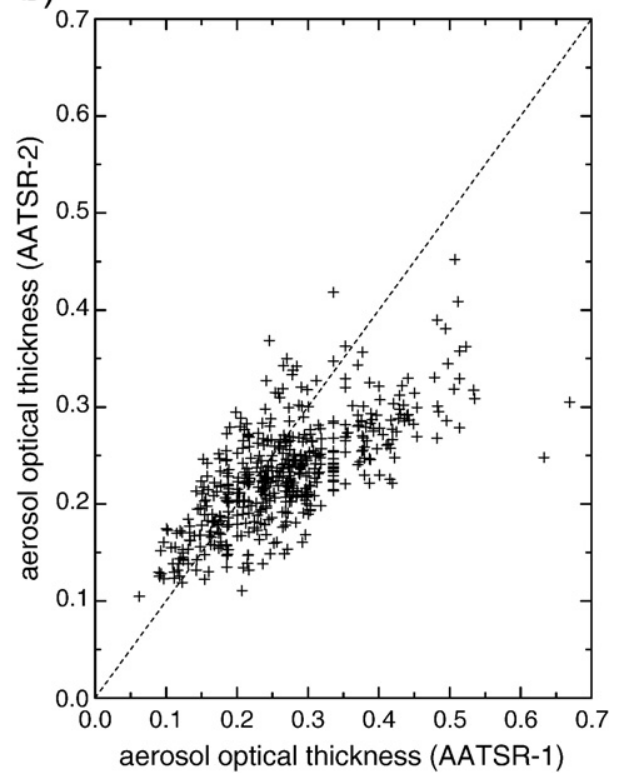

d)

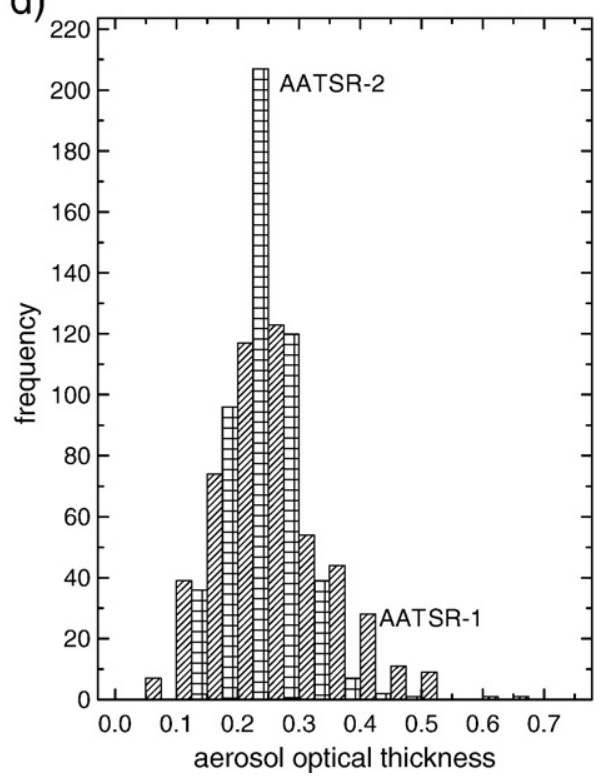

Fig. 2. a) The example of the spatial match algorithm results. Stars give the positions of corners of $10 \times 10 \mathrm{~km}^{2}$ AOT scenes derived using AATSR-1 algorithm and squares give centers of AATSR-2 - derived AOTs scenes having the spatial resolution $3 \times 3 \mathrm{~km}^{2}$. b) The correlation of AOTs derived using diverse dual-view algorithms for AATSR. c) The correlation of AOT differences defined as (AOT(AATSR-2)-AOT(AATSR-1))/AOT (ATSR-1) with AOT (ATSR-1). d. The frequency distributions of derived AOTs for AATSR-1 and AATSR-2 algorithms.

algorithm. AATSR-1 data in Fig. 2b-d corresponds to the algorithm of Grey et al. (2006b) and AATSR-2 data corresponds to the algorithm of Thomas et al. (in preparation). Both algorithms use the dual viewing capability of AATSR but in a different way as outlined above. The spatial resolution of correspondent AOT datasets is $10 \times 10 \mathrm{~km}^{2}$ for AATSR- 1 and $3 \times 3 \mathrm{~km}^{2}$ for AATSR-2 and AATSR-3. Resampling of higher resolu- tion data has been performed to colocate these measurements (see Fig. 2a). The AOTs derived using the different algorithms correlate well for the values of AOT smaller than 0.3 (see Fig. 2b), but deviate at larger AOTs. Some of this discrepancy may be because different aerosol models were used. AATSR-1 produces larger AOTs on average $(0.26 \pm 0.1$ as compared to $0.23 \pm 0.05$ for AATSR-2, see Fig. $2 b-d)$. The 
histograms of retrieved AOT as shown in Fig. 2d are similar for both retrievals. The difference for retrievals of AOTs smaller than 0.25 common for most of European sites at the moment of measurements is less than 30\% (see Fig. 2c). Therefore, we conclude that both dual viewing algorithms produce consistent results for typical continental aerosol load conditions. Retrieved
AOTs higher than 0.3 may be contaminated by sub-pixel cloudiness or extended cirrus fields.

The difference in AOTs as retrieved for the same ground pixel but using different AATSR measurement modes and algorithms (AATSR-2,3) is given in Fig. 3. The AATSR-3 algorithm has been used to generate AOT of nadir and forward scans of AATSR and also the
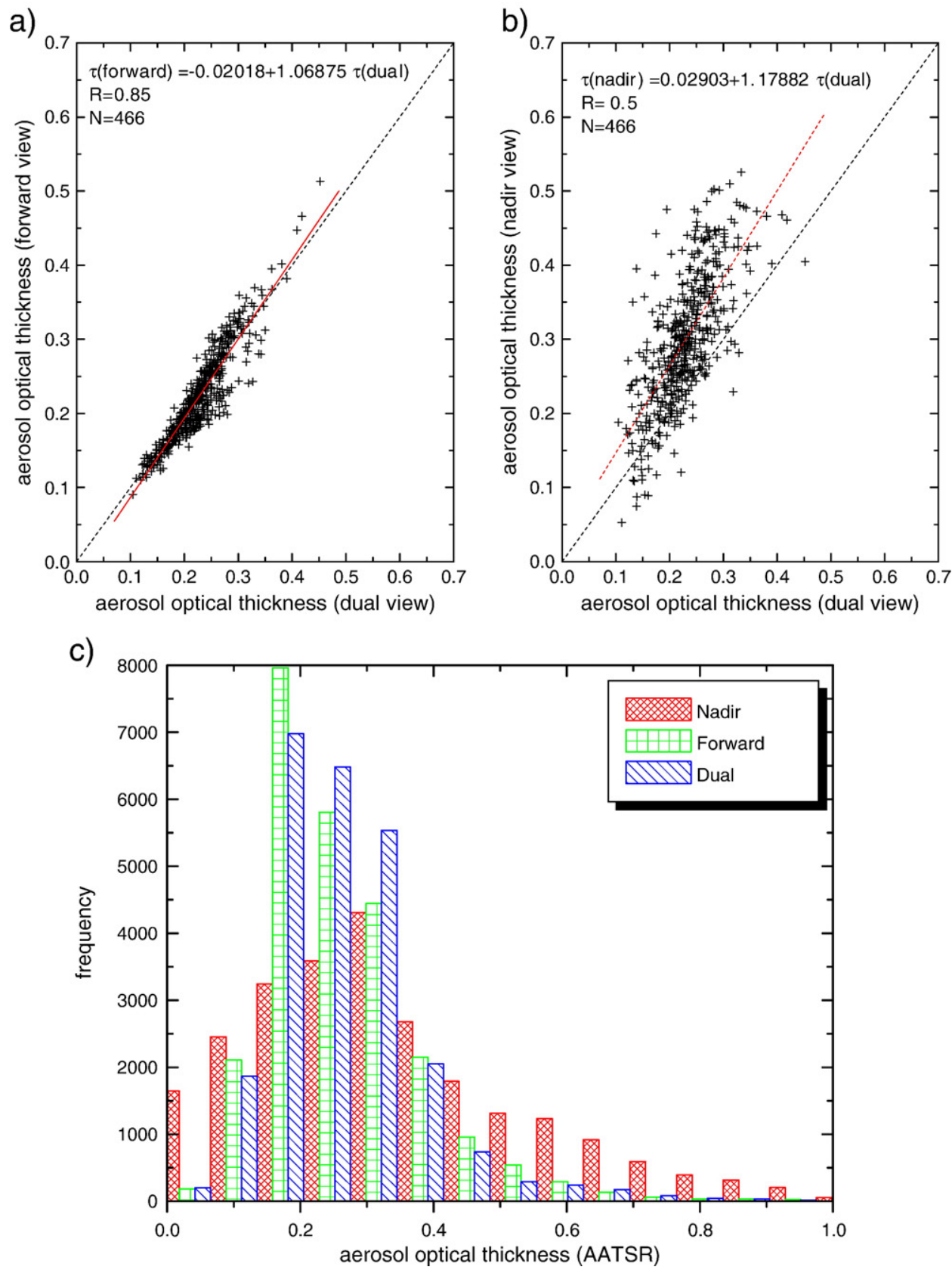

Fig. 3. a) The correlation of AOTs derived using ORAC in the dual-view and forward view retrieval modes. The correlation coefficient $R$ is equal to 0.85 for the selected 466 AOT pixels. b) The same as in (a) except for the nadir view. c) The frequency distributions of derived AOTs for ORAC single and dual-view algorithms. 
AATSR-2 dual-view algorithm has been applied for the same ground scenes.

It follows that the processing of the forward view gives the smallest AOTs. The largest AOTs are for the nadir observation mode. The dual-view produces results which are located between these two retrievals. The differences are most probably due to the influence of the surface treatment but also due to the phase function effects. It follows from the comparison of Fig. 3a and b that the correlation of the forward view retrieval results with the dual-view retrieved AOTs is much better as compared to the correlation of AOTs obtained from nadir AATSR-3 and dual-view AATSR-2 algorithms. This is related to the fact that the forward view corresponds to a larger atmospheric path as compared to the nadir view. Therefore, the sensitivity to the aerosol is increased for the forward view geometry. The opposite is true for the nadir scan.

The histograms of SCIAMACHY AOT retrieved using the ASP algorithm and collocated AATSR-1 retrievals are shown in Fig. 4. The average AOT is $0.17 \pm 0.2$ for SCIAMACHY. The mean is not a representative value for SCIAMACHY because most retrievals have low values and there is a long tail of high AOT (see Fig. 4). So the standard deviation $\sigma$ is almost equal to the average value $\bar{\tau}$ and the coefficient of variance $(\sigma / \bar{\tau})$ is equal to $85 \%$.

As described above, SCIAMACHY retrieval produces AOT at $0.5 \mu \mathrm{m}$ and the class parameter containing also aerosol Ångström coefficient. Exponential inter- polation in wavelength has been made to obtain AOT at $0.55 \mu \mathrm{m}$. The SCIAMACHY algorithm underestimates the aerosol optical thickness as compared to AATSR. This behavior confirms the overall trend of SCIAMA$\mathrm{CHY}$ in underestimating the columnar aerosol burden found by Di Nicolantonio et al. (submitted for publication) in comparing SCIAMACHY zonal monthly averaged AOT to the respective official NASA MODIS AOT. This can be related to the SCIAMACHY processor 5 calibration problems. It is known that SCIAMACHY reflectances for the current version processor 5 are too low as compared to those of AATSR (Jourdan et al., 2007) and MERIS (Acarreta and Stammes, 2005). For this reason, ASP algorithm uses the TOA reflectance correction derived by a linear regression fit in a SCIAMACHY-MERIS reflectance comparison. As emphasized in Acarreta and Stammes (2005), this correction does not take into account nonlinear effects pertaining to measured TOA reflectance lower than 0.2 in the UV-VIS spectral range. This means that the applied linear correction is not able to reconstruct the SCIAMACHY measured signal in presence of low aerosol loadings which, consequently, are still underestimated by ASP. The new SCIAMACHY Processor version 6 will be implemented in 2007, making use of officially re-calibrated version of Level $1 \mathrm{~B}$ data in order to improve the consistency of reflectance measurements and then increase the accuracy of the aerosol retrieval.

Note that number of colocated pixels analyzed is different for Figs. 2c, 3, and 4. So a direct comparison of

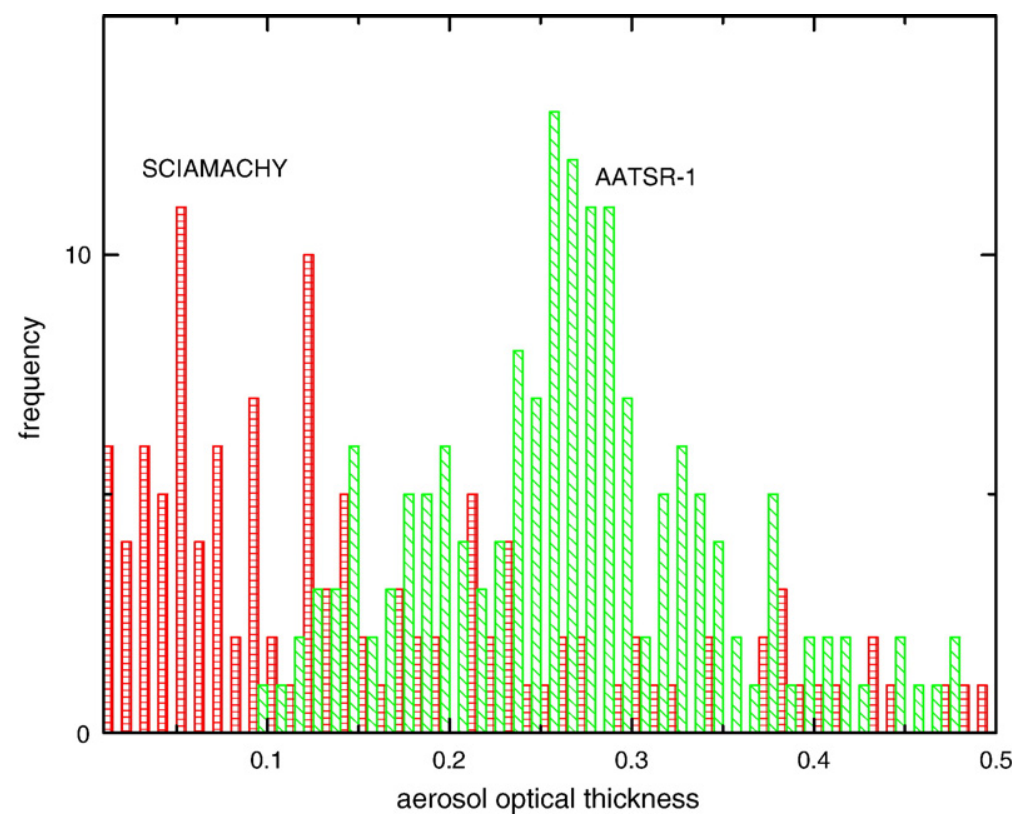

Fig. 4. The frequency distributions of derived AOTs for AATSR-1 and SCIAMACHY algorithms. 
averages cannot be performed due to the use of different statistical ensembles. However, the general trend is clearly seen.

The results of colocated BAER MERIS and AATSR1 retrievals are given in Fig. 5. Fig. 5a shows the location of AATSR $10 \times 10 \mathrm{~km}^{2}$ ground scenes and also collocated $1 \times 1 \mathrm{~km}^{2}$ MERIS scenes. The BAER MERIS gives smaller values of AOT $(0.18 \pm 0.03$ as compared to AATSR-1 retrievals (see also Fig. 2c). However, they are larger as compared to SCIAMACHY retrievals. Fig.

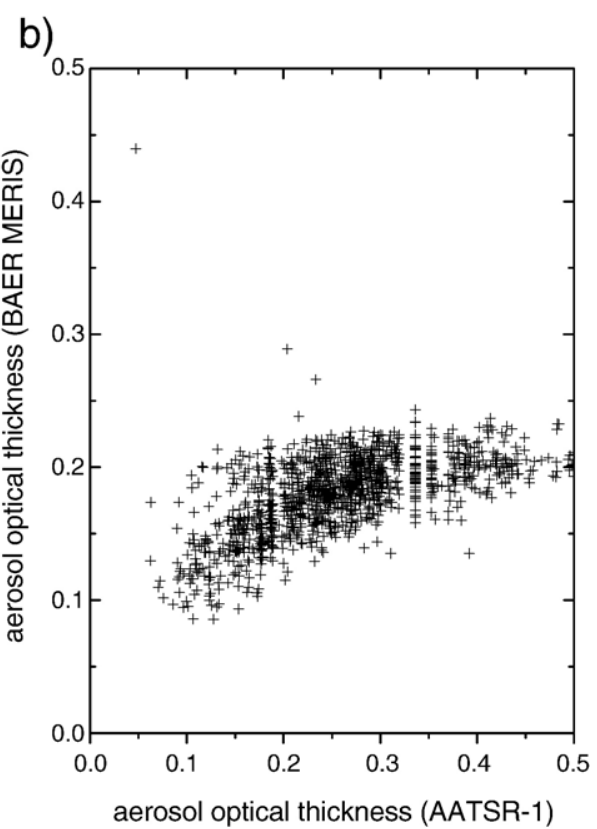

d)

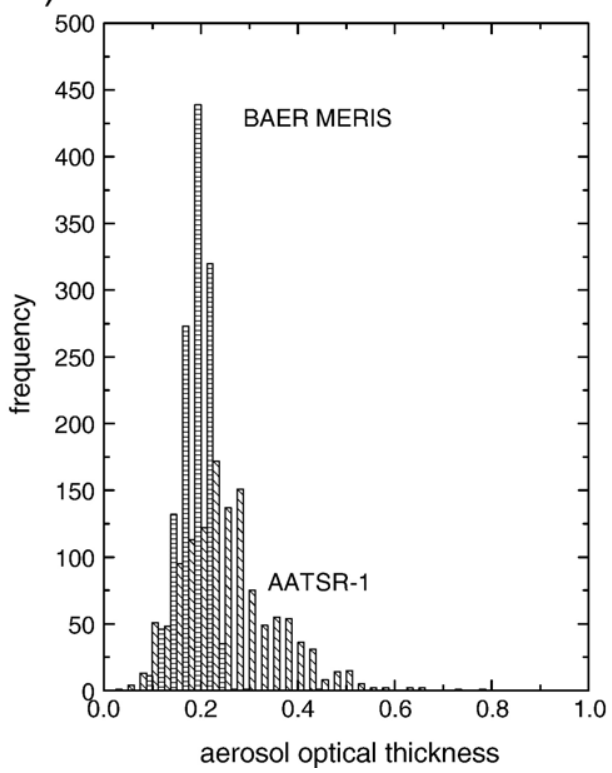

Fig. 5. a) The studied area and the results of the pixel match algorithm. This area is used for the inter-comparison of MERIS and AATSR retrievals in this paper. Squares correspond to the corners of $10 \times 10 \mathrm{~km}^{2}$ AATSR-1 scenes used in the paper to report AOT. Black points correspond to centers of MERIS $1 \times 1 \mathrm{~km}^{2}$ pixels inside of AATSR scenes. Holes in the figure give missing AOT data. The same area was used in the comparison for other instruments except the white area in the left part of this figure was filled by measurements as well. The reason for the mismatch is the fact that the swath of AATSR is rather narrow as compared, e.g., to MERIS. b) The correlation of AOTs derived using BAER MERIS and AATSR-1 algorithms. c) The correlation of AOT differences defined as (AOT(AATSR-1)-AOT(BAER MERIS))/AOT (BAER MERIS) with AOT (ATSR-1). d) The frequency distributions of derived AOTs using AATSR-1 and BAER MERIS algorithms. 
$5 \mathrm{~b}$ shows that BAER MERIS and AATSR AOTs correlate well for smaller AOTs. However, there is a poor correlation at AOTs larger than approximately 0.3. Differences between single retrievals are in the range $[-50 \%, 50 \%]$ at AOT $<0.3$. These differences can be due to uncertainties in a priori information as described above (e.g., the phase function, single scattering albedo, ground reflectance).

The official ESA MERIS AOT product (Santer et al., 1999 ) is in the range $0.05-0.25$. The average AOT is close to AOT derived with BAER MERIS (see Figs. 6 and 7) for the region 7-12E, 49-53N. However, there is no significant correlation between the two products for the region studied even though they use the same set of reflectance values in the retrieval procedure. This is true on a pixel-by-pixel basis (Fig. 6a) and for half-degree averages (Fig. 6b). Such a discrepancy may be related to
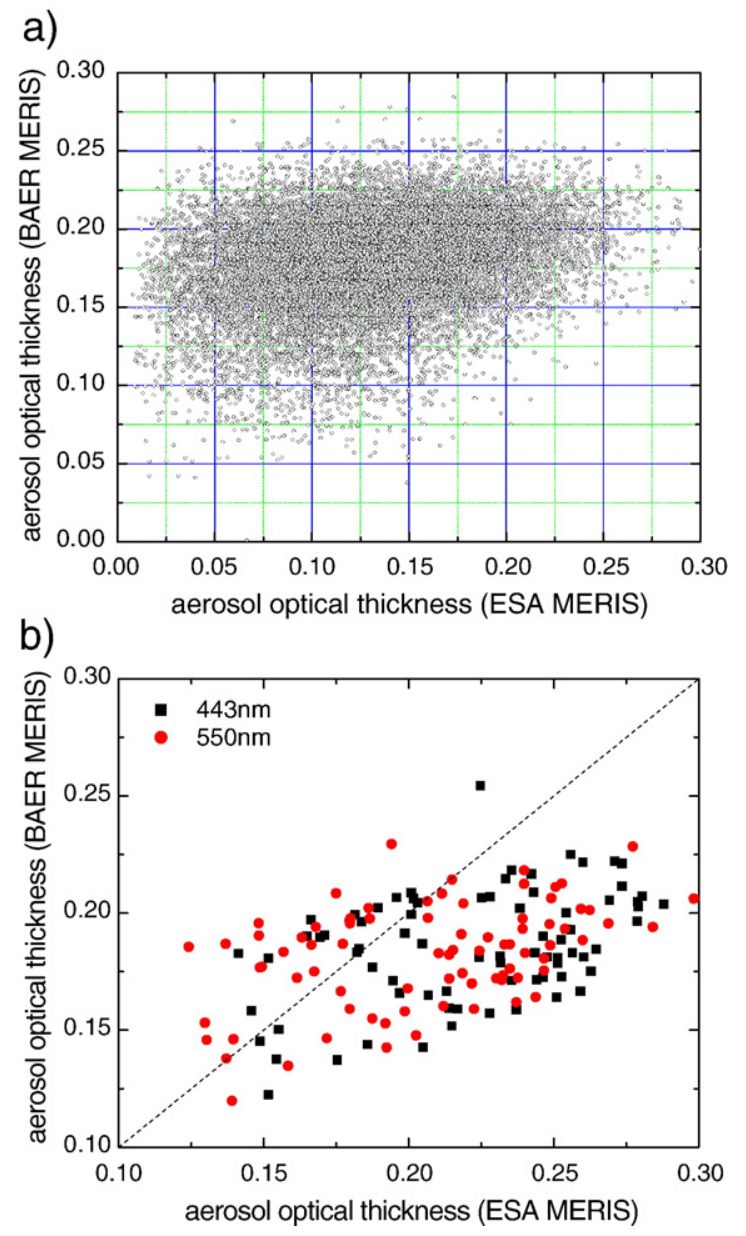

Fig. 6. a) The correlation of AOTs derived using ESA and BAER MERIS algorithms for the area 7-12E, 49-53N. b) The same as in (a) except for the average AOTs. The areas $0.5^{\circ} \times 0.5^{\circ}$ were used for the averaging of satellite-derived AOTs. the different treatment of the surface reflectance and aerosol scattering in both retrieval procedures. The official ESA AOT product contains AOT at the wavelength $\lambda=0.443 \mu \mathrm{m}$ and the Ångström exponent $\alpha$. Therefore, the relationship $\operatorname{AOT}(\lambda=0.55 \mu \mathrm{m})=\mathrm{AOT}$ $\left(\lambda_{0}=0.443 \mu \mathrm{m}\right)\left(\lambda / \lambda_{0}\right)^{-\alpha}$ has been used to obtain AOT at the longer wavelength. The bias in the retrieved $\alpha$ by the ESA MERIS algorithm can contribute to the differences shown in Fig. 7. Similar problems exist for BAER MERIS. Generally errors of both algorithms increase with the wavelength due to the increase in the ground surface contribution in the measured signal. The difference in AOTs correlates with the ESA MERIS AOT (see Fig. 8). Most of differences are in the range $[-0.1,0.1]$. This is a significant difference considering the fact the same observations are used in the retrieval procedure. This clearly shows that the information content of the spectral measurements is quite poor and different a priori constraints lead to different retrieval results. The average AOT for AATSR algorithms is larger as compared to both MERIS algorithms. A part of the difference can be due to the different calibration and cloud screening algorithms for both instruments.

Average AOT for ESA MERIS retrievals is equal to $0.13 \pm 0.05$ as compared to $0.18 \pm 0.03$ for BAER MERIS retrievals for the region $7 \mathrm{E}-12 \mathrm{E}, 49 \mathrm{~N}-53 \mathrm{~N}$. We conclude that ESA MERIS retrieval is shifted to smaller AOT as compared to BAER MERIS (see Fig. 7). Also standard deviations of AOT in the region studied are larger for ESA MERIS algorithm. Values of AOT smaller than 0.05 are almost absent in both retrievals. This is similar to AATSR but not to SCIAMACHY retrievals. The distribution of AOT for BAER MERIS is closer to AATSR AOT distributions (see Figs. 2c and 7) as compared to ESA MERIS AOT product.

It is difficult to select the best ENVISAT AOT product from the inter-comparison study performed above. However, some indications of their quality can be obtained from comparisons with instruments on other satellite platforms and also using ground measurements. This is considered in the following sections.

\subsection{MISR and MODIS on board TERRA and POLDER on board PARASOL}

The comparison of MISR and ESA MERIS/BAER MERIS products for spatially collocated pixels in the region $7-12 \mathrm{E}, 49-53 \mathrm{~N}$ is shown in Fig. 9. The time difference between the two measurements is $30 \mathrm{~min}$. MISR gives smaller values of the average AOT $\bar{\tau}$ for the area $(0.14 \pm 0.03)$ as compared to BAER MERIS, but MISR $\bar{\tau}$ is close ESA MERIS retrievals. On the other 


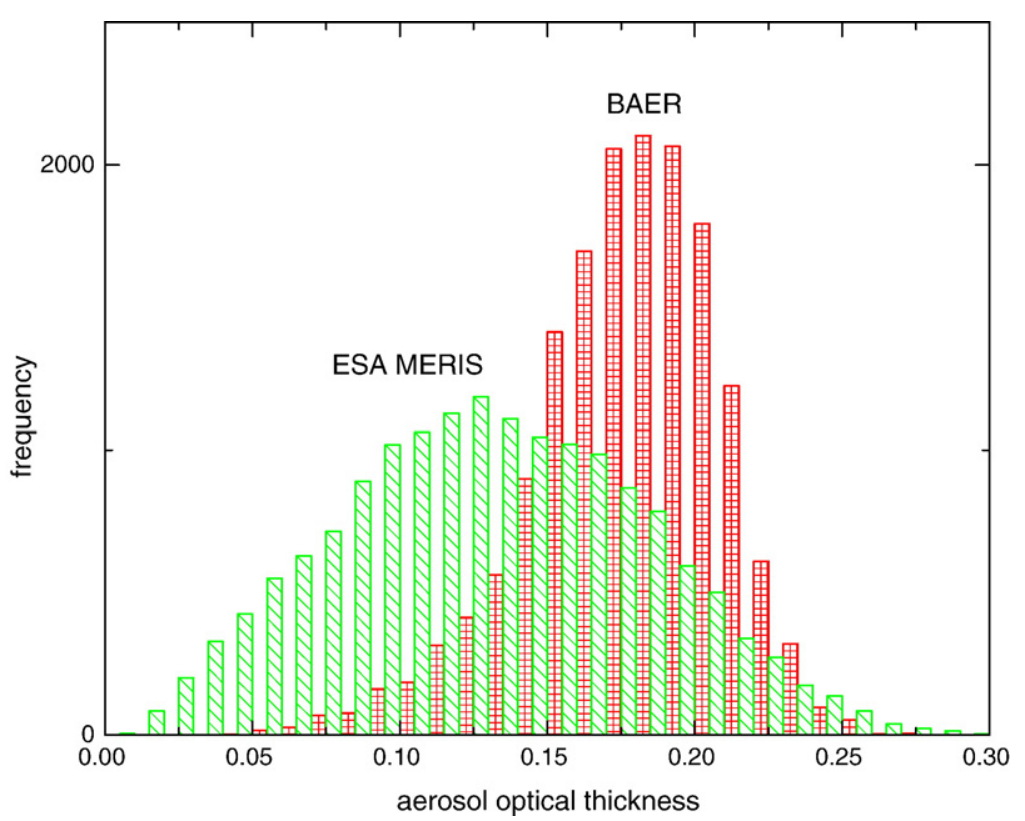

Fig. 7. The frequency distributions of derived AOTs for ESA and BAER MERIS algorithms.

hand, BAER MERIS retrievals are better correlated with MISR retrievals (see Fig. 9a), although the frequency distribution of ESA MERIS AOT is closer to that of MISR (see Fig. 9c).

The results obtained from MISR deviate considerably from those of AATSR independently on the AATSR algorithm used. The average value of MISR AOT differs by 0.04 from BAER MERIS retrievals and differs by just 0.01 from ESA MERIS retrievals. The correlation of BAER MERIS AOT with that of MISR is better as compared to the case of BAER-ESA MERIS AOT correlation. There is a clear correlation of the differences

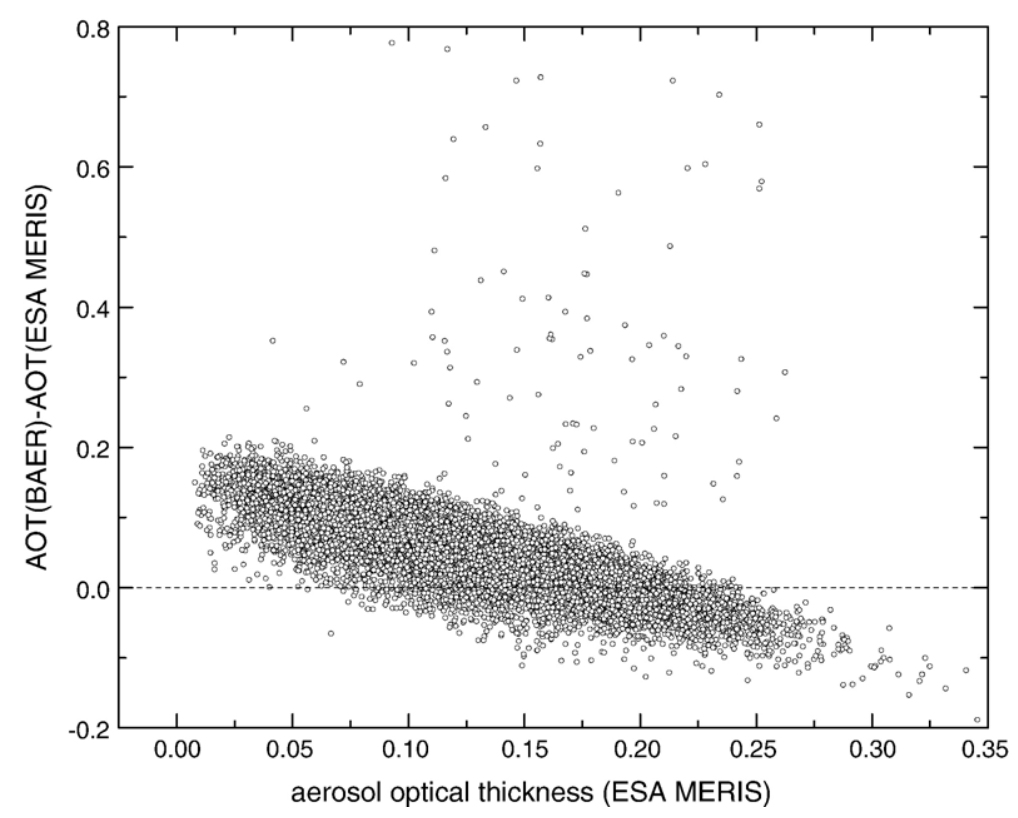

Fig. 8. The correlation of differences AOT(BAER-ESA) with AOT (ESA MERIS). 
a)

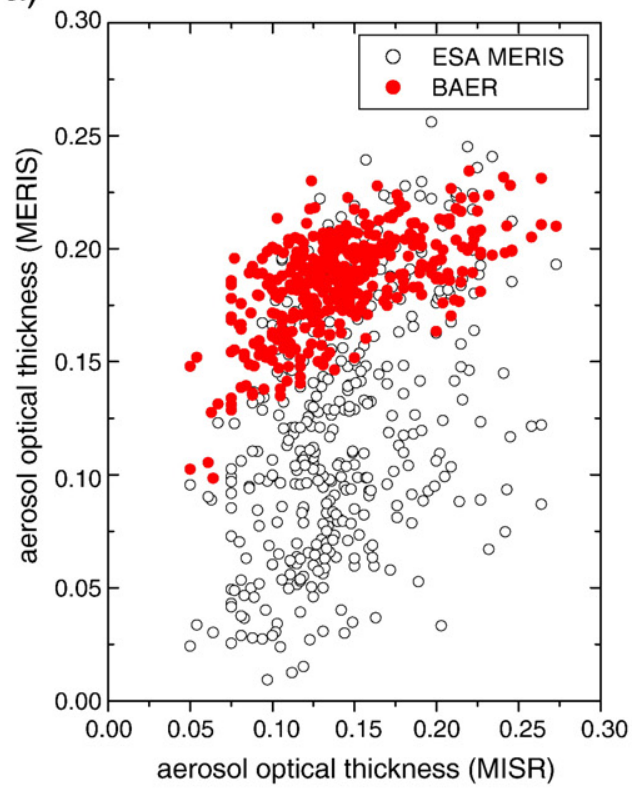

b)

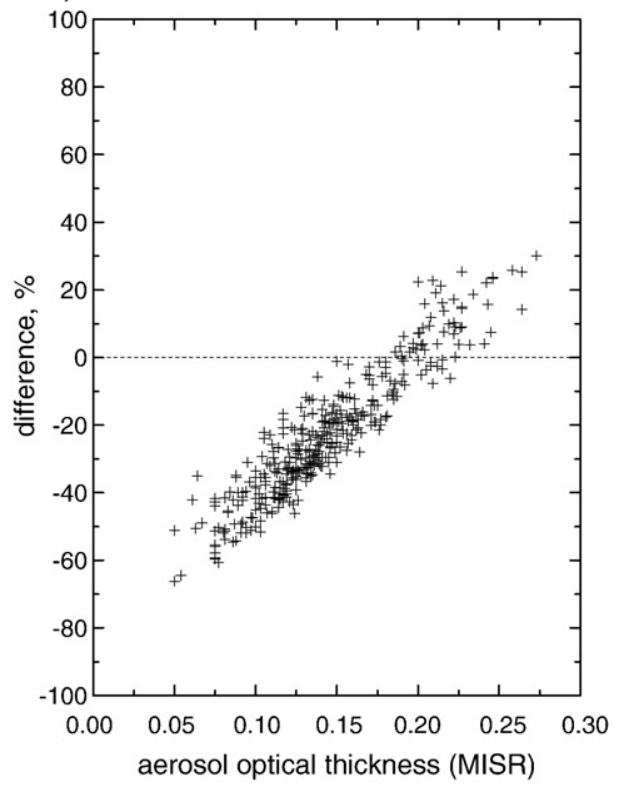

c)

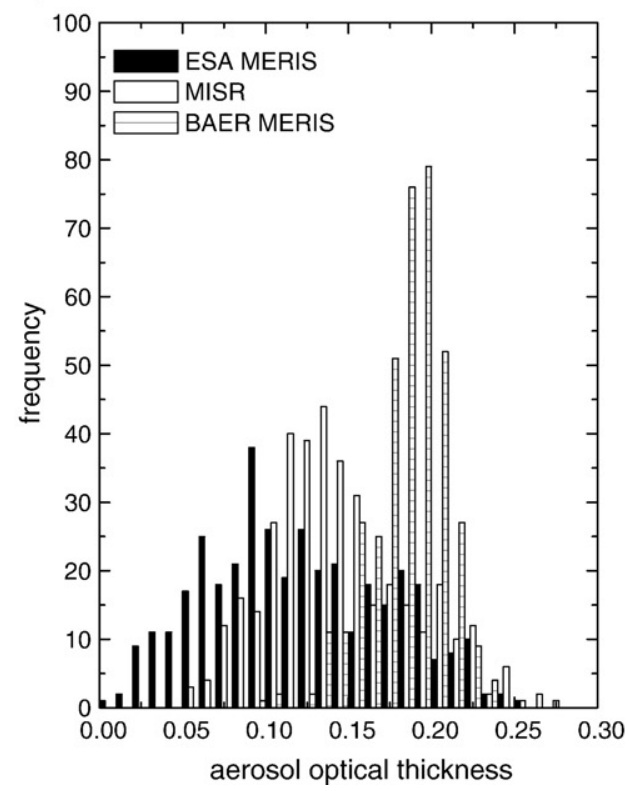

Fig. 9. a) The correlation of AOTs derived using MERIS and MISR. Filled circles give the results of BAER MERIS algorithm and open circles give results of ESA MERIS algorithm. b) The correlation of AOT differences defined as (AOT(MISR)-AOT(BAER MERIS))/AOT (BAER MERIS) with AOT (MISR). c) The frequency distributions of MERIS and MISR-derived AOTs.

$D=($ AOT $($ MISR $)-$ AOT $($ BAER MERIS $)) /$ AOT (BAER MERIS) shown in Fig. 9b with MISR AOT.

AOT derived from POLDER at $0.55 \mu \mathrm{m}$ cannot be directly compared with data given above because POLDER algorithm derives not total AOT but only the part related to the fine mode. Also POLDER on board PARASOL flies approximately 90 min behind ENVISAT. So the aerosol load and properties can change as compared to those derived from ENVISAT instruments depending on the meteorological conditions and also other factors including anthropogenic aerosol life cycle. The corresponding spatial distribution of 


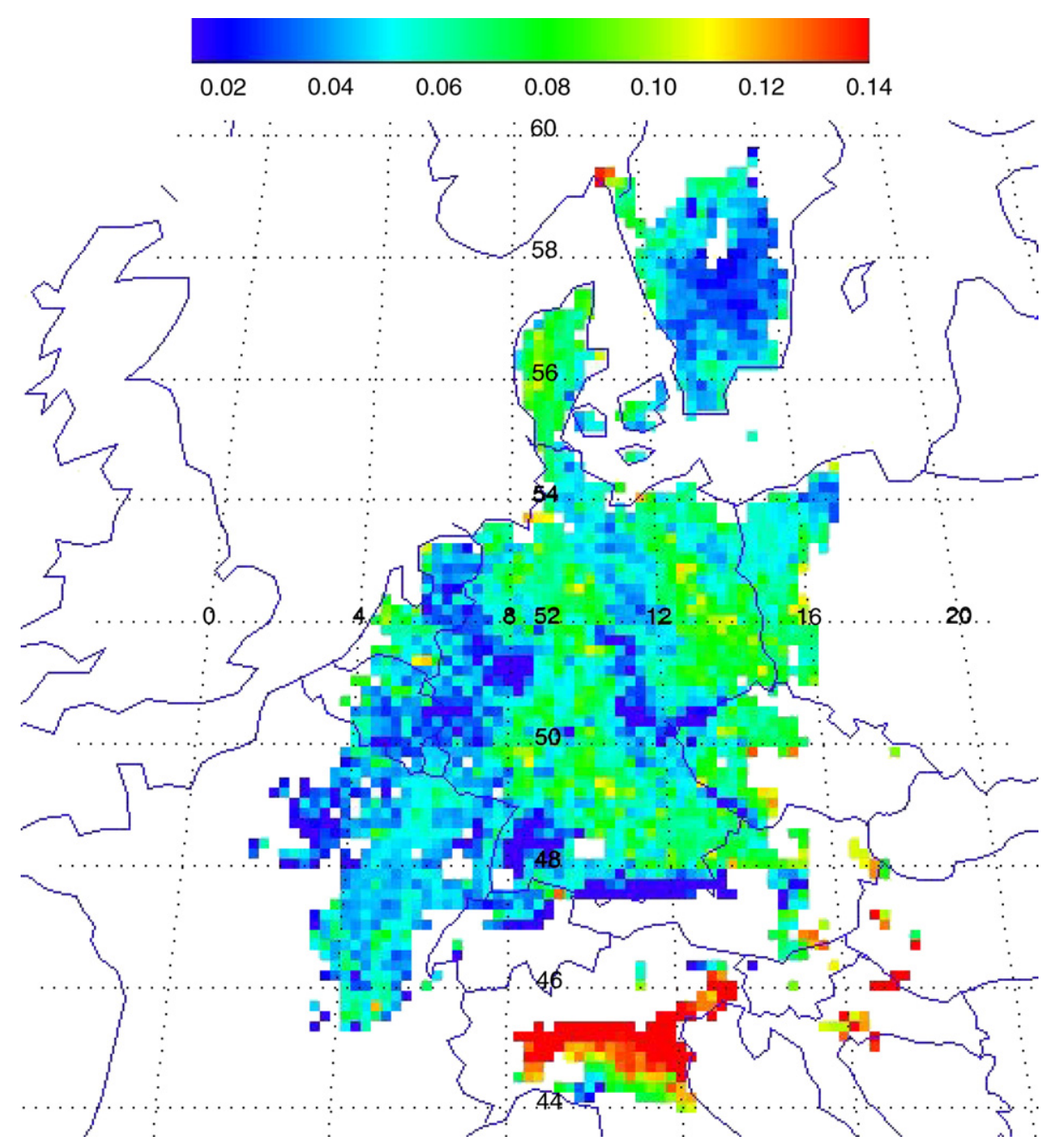

Fig. 10. The map of AOT $(550 \mathrm{~nm})$ derived by POLDER.

AOT is shown in Fig. 10. Generally AOT is quite low and deviate considerably from MERIS and AATSR retrievals. As expected, the average AOT (0.1) is smaller than that retrieved by BAER MERIS algorithm. The collocated BAER MERIS retrievals correlate with those of POLDER on board PARASOL as shown in Fig. 11 for the region 7-12E, 49-53N.

MISR and MODIS are on the same space platform, so they measure at the same place and time. Ideally, retrievals from both instruments would give similar results. Indeed the correlation of both measurements is quite high as shown in Fig. 12 for the area 7-12E, 49$53 \mathrm{~N}$. However, there are some differences, which are due to different information content and a priori assumptions in both algorithms. The correlation of MBAER retrievals with those from MISR is not so strong as the MISR-NASA MODIS correlation (see
Fig. 13). In particular, AOTs larger than 0.2 are absent in MISR and NASA MODIS retrievals but they are present in MBAER retrievals, which can be related to surface reflectance estimations, aerosol models and cloud screening algorithms, which differ depending on the retrieval technique used. Also there is some disagreement in AOT spatial patterns as retrieved by the MBAER and NASA MODIS algorithms (see Fig. 14). The statistical distribution of AOTs retrieved using MISR, MODIS-MBAER, and NASA MODIS algorithms is shown in Fig. 15. They are quite similar to MERIS retrievals (see Fig. 7) but different from AATSR retrievals (see Fig. 2c). The average values of AOT both for MISR and NASA MODIS retrievals are equal to 0.14 for the area $\mathfrak{R} \in[7-12 \mathrm{E}, 49-53 \mathrm{~N}]$ with similar standard deviations of AOT spatial distributions (0.04), which implies that the variation of the aerosol optical 
a)

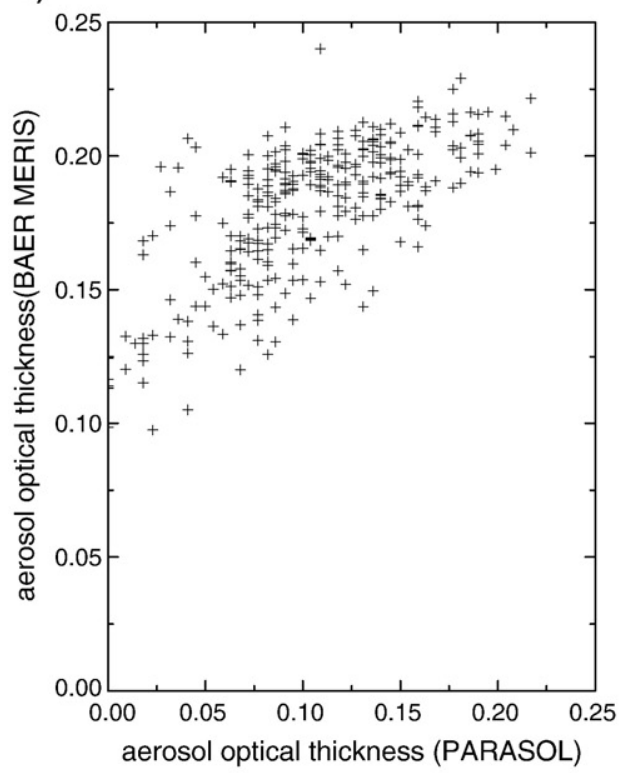

b)

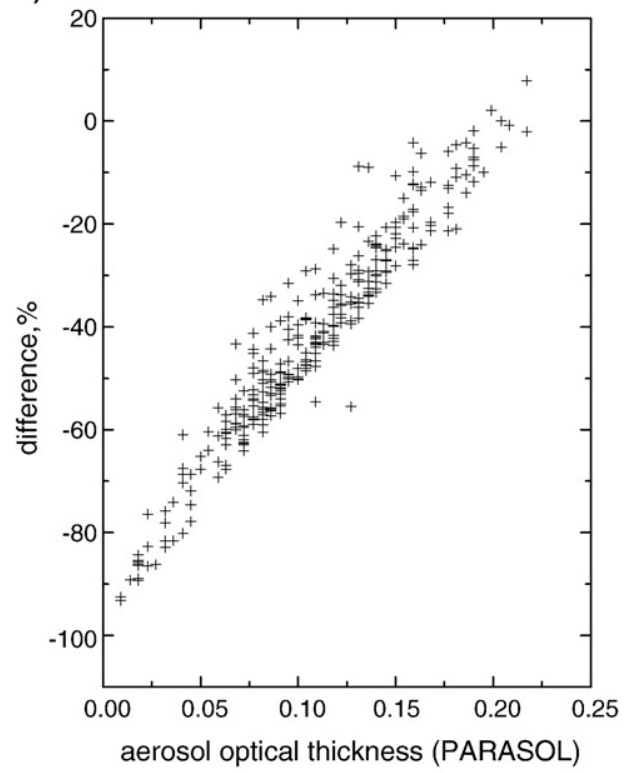

c)

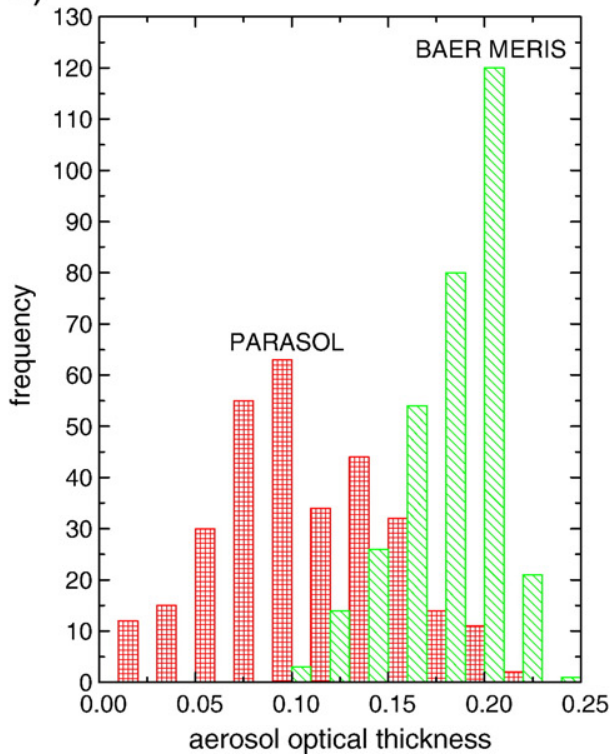

Fig. 11. The same as in Fig. 2 except for BAER MERIS and POLDER PARASOL algorithms.

thickness in the area $\mathfrak{R}$ is quite small (the coefficient of variance is about $30 \%$ ). MBAER MODIS gives the value of AOT equal to 0.15 for the same area with the standard deviation equal to 0.06 .

The POLDER on board PARASOL measurements give the average AOT of 0.1 and, if we assume, that MISR average AOT of 0.14 is correct, it follows that the fine mode contributes $\approx 70 \%$ to the total value of $\mathrm{AOT}$, which is a reasonable estimate for the case studied.

\subsection{Inter-comparisons for a small cloudless scene}

Most of the results presented above were concerned with comparisons and correlations of results from just two instruments for spatially collocated pixels. This is because it is not possible to have a complete spatial match of measurements by all instruments for the whole area studied. On the other hand, it is of importance to compare the results of all algorithms obtained from all 


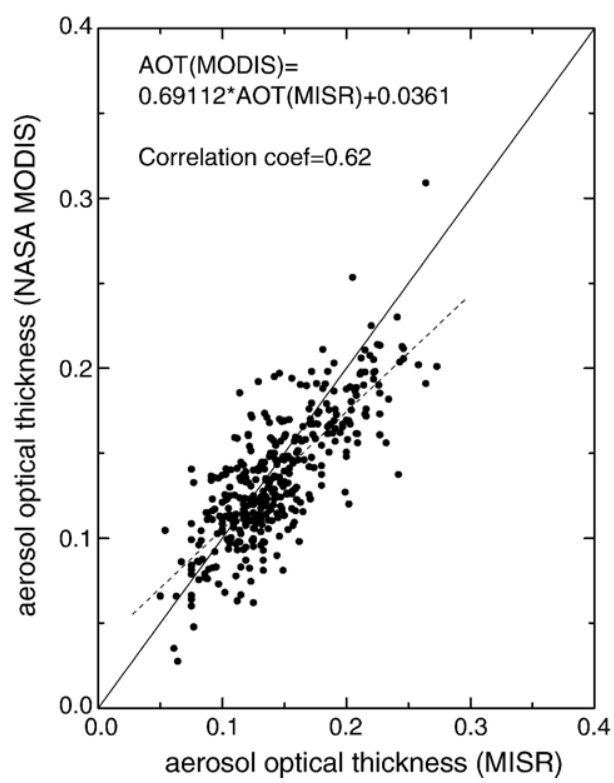

Fig. 12. The correlation of AOTs derived using NASA MODIS and MISR algorithms.

instruments for a given ground scene. This question is considered in this Section for an area 9E-11.5E, $52 \mathrm{~N}-$ $52.5 \mathrm{~N}$, where all instruments performed measurements (with some time differences as indicated in Table 1). Most of the area under study is covered by vegetation, mostly forest. The area is bounded from the south by Harz hills covered by forest, and also includes the urban areas of Hannover, Wolfsburg, Hildesheim, and Braunschweig. The results of average AOTs at $0.55 \mu \mathrm{m}$ for this area are given in Table 4 .

The analysis of data presented in Table 4 enables the following conclusions. The average AOT as retrieved using different instruments is in the range 0.15-0.22 (with the exception of AATSR-2 algorithm). This is similar to the average value of AOT close to 0.2 characteristic for the region studied as obtained from ground measurements (see Table 3). This enables the conclusion that average satellite retrieved AOTs correspond quite well to ground measurements, and also they are close to each other. Differences can occur, however, on pixel-by-pixel basis as indicated in the previous sections.

AOT retrieved by POLDER is quite small $(0.16)$ and close to MISR (0.16) and MODIS-NASA (0.15) values. If retrievals from all three instruments are correct, one can conclude that the contribution of the coarse mode to AOT is quite low for the scene studied. Some of the differences are due to the fact that PARASOL flies approximately $1 \mathrm{~h}$ after TERRA. So there is a temporal mismatch of these measurements of AOT.
Most of algorithms for the ENVISAT instruments give AOT around 0.2. This gives some room for a coarse mode (about $30 \%$ of AOT) if one neglects possible aerosol transformation processes between the ENVISAT and PARASOL overpasses. As a matter of fact, the temperature rose from $14{ }^{\circ} \mathrm{C}\left(10: 00\right.$ UTC) to $17{ }^{\circ} \mathrm{C}$ (13:30 UTC) (http://www.wetterzentrale.de/topkarten/ fsbeobl.html) on the day of measurement for the most of the studied area. This change, and also the change in illumination conditions, can lead to different values of retrieved AOT between PARASOL and ENVISAT instruments.

The official NASA MODIS AOT product for the area studied is smaller by 0.06 as compared to official ESA product. This is inside of the error bar of MODIS AOT product $\left( \pm 0.08\right.$ for $\tau_{\mathrm{a}}=0.15$ (Chu et al., 2002)).

The estimate of average AOT over the scene for AATSR-1 is higher than the other satellites' estimates because the value of single scattering albedo (SSA) used in the aerosol model was underestimated compared with the other retrievals. This was tested using a higher value of SSA corresponding with non-absorbing aerosols that resulted in a more consistent value of mean AOT compared with the other satellites' estimates.

This highlights the difficulty in performing intercomparisons between established aerosol products and processing set ups because not only are the datasets and algorithms themselves being compared but also other issues such as cloud masks, radiative transfer models,

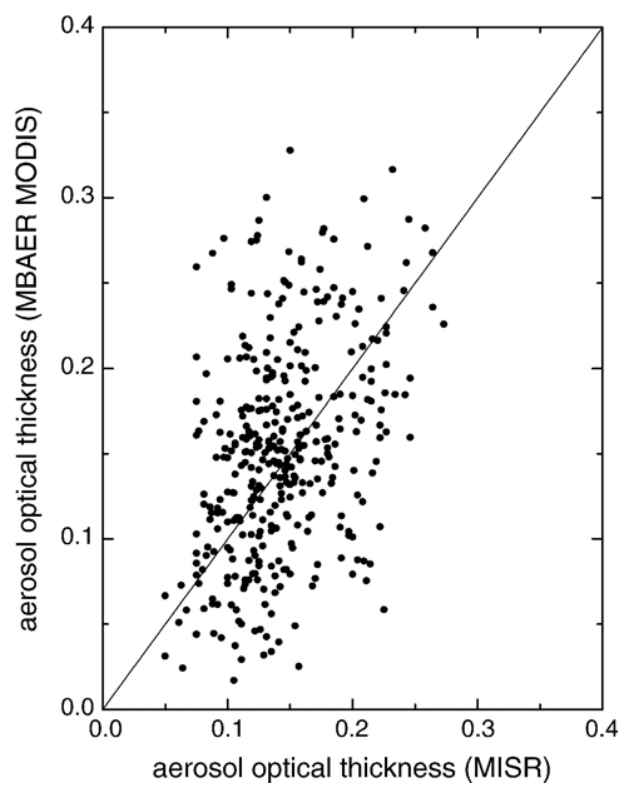

Fig. 13. The correlation of AOTs derived using MBAER MODIS and MISR algorithms. 

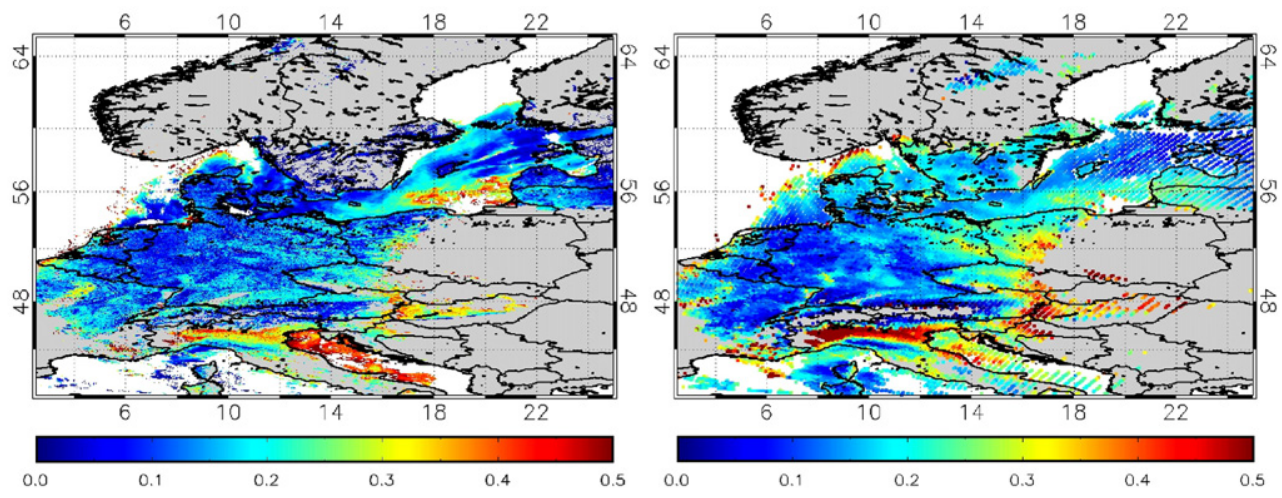

Fig. 14. The spatial distribution of AOT obtained using MBAER (left) and NASA (right) MODIS algorithms.

atmospheric properties, aerosol models and other parameter assumptions are being incorporated in the comparison and influencing the retrievals of AOT. This makes it difficult for us to perform direct comparisons of algorithms and datasets because the effects of several components are mixed up in the analysis.

\subsection{Comparisons with AERONET}

Here, we perform comparisons with AERONET because they allow us to validate our satellite-derived aerosol properties and provide a benchmark for the performance for each algorithm and instrument combination. Inter-comparisons between satellite products,

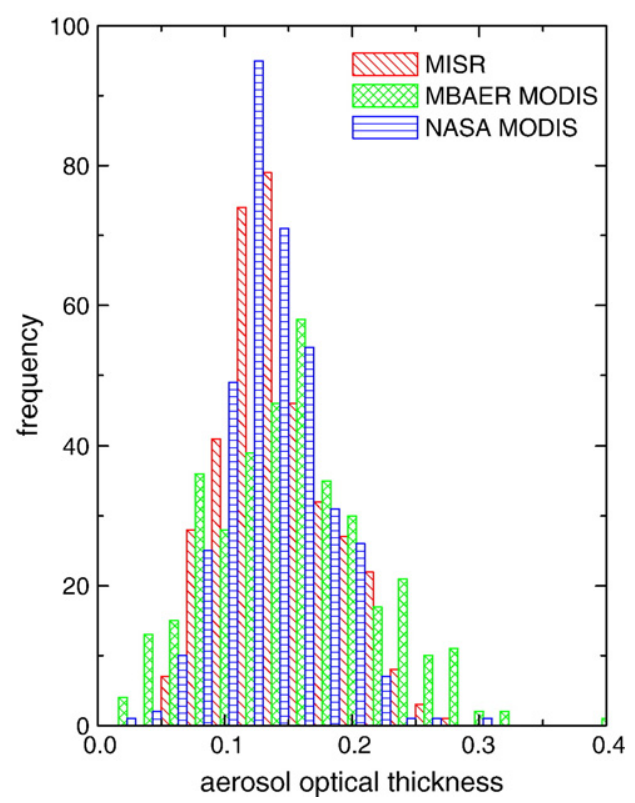

Fig. 15. The frequency distributions of derived AOTs for MISR, MBAER MODIS and NASA MODIS algorithms. while useful, only give us an indication of internal consistency and do not allow us to perform robust validation. AERONET (Holben et al., 1998) is a network of identical sun photometers designed specifically for the validation of satellite aerosol retrievals. Several instruments were in operation on the ground simultaneously with satellite measurements. The correlation of AERONET and satellite measurements for different instruments is given in Fig. 16. Data from AERONET stations located in the central Europe has been used in the analysis (see Table 3). One concludes that very small optical thickness as determined by SCIAMACHY and also by POLDER is not confirmed by ground measurements. A similar AOT underestimation by SCIAMACHY was found by Di Nicolantonio et al. (submitted for publication) in an extensive AERONET comparison for AOT lower than 0.2, while showing SCIAMACHY capability to better detect aerosol hot spot and global pattern of aerosol loading.

The aerosol optical thickness is in the range of 0.150.30 as determined by the most of instruments in the region studied. AATSR retrievals generally overestimate AOT as compared to AERONET. MISR and POLDER give underestimation of AOT at larger values of AOT (>0.25, see Fig. 16) and MERIS algorithms have the best overall correlation with ground-based measurements. The dispersion of AOT retrieved using different instruments and algorithms is large for AERONET sites (see Fig. 16).

\section{Conclusions}

In this work we have compared spatially collocated measurements of AOT at $0.55 \mu \mathrm{m}$ derived from top-ofatmosphere reflectance measurements by various satellite optical instruments for a region in central Europe. Results from ten algorithms (see Table 2) were inter- 
Table 4

Statistical characteristics of retrieved AOT at $0.55 \mu \mathrm{m}$ for the area 911.5E, $52-52.5 \mathrm{~N}$ (October 13th, 2005)

\begin{tabular}{lll}
\hline Instrument/algorithm & Average AOT & Standard deviation \\
\hline MODIS/NASA & 0.15 & 0.03 \\
MISR/JPL & 0.16 & 0.02 \\
POLDER & 0.16 & 0.04 \\
MERIS/BAER & 0.20 & 0.02 \\
MODIS/BAER & 0.20 & 0.01 \\
MERIS/ESA & 0.21 & 0.05 \\
AATSR-2 & 0.22 & 0.06 \\
AATSR-1 & 0.30 & 0.05 \\
\hline
\end{tabular}

compared. MISR, MERIS, and MODIS retrievals generally agree. MERIS retrievals agree best with the ground measurements for several AERONET stations located in central Europe. SCIAMACHY retrievals are least accurate as compared to the ground measurements.

The average aerosol optical thickness at $0.55 \mu \mathrm{m}$ for October 13th, 2005 in the northern Germany (7-12E, $49-53 \mathrm{~N}$ ) was equal to 0.13 for ESA MERIS AOT algorithm and 0.14 for both MISR and NASA MODIS algorithms. MBAER MODIS and BAER MERIS gave 0.15 and 0.18 , respectively, for the same area. The average AOT retrieved from SCIAMACHY was found to be equal to 0.17 with a large coefficient of variance $(85 \%)$. Generally, these numbers agree quite well. Although the average values of AOT obtained from different instruments are similar, large differences on pixel-by-pixel basis were found in a number of cases.
For a smaller area located at 9-11.5E, $52-52.5 \mathrm{~N}$, MODIS/NASA and MISR retrievals gave the optical thickness at $0.55 \mu \mathrm{m}$ equal to 0.15 and 0.16 , respectively. MERIS and AATSR retrievals on ENVISAT (with exception of AATSR-1 algorithm) gave $\tau_{\mathrm{a}}=0.2-0.22$ for the same area but $30 \mathrm{~min}$ before in time. The difference of AOT between TERRA and ENVISAT instruments is inside MODIS NASA AOT predicted error $( \pm 0.08$ for the case studied, see Chu et al. (2002)). Importantly, MERIS and AATSR (with exception of AATSR-1 algorithm) gave close values of AOT $(\approx 0.2)$ for the region studied. The same is true for MISR and MODIS instruments on TERRA (with exception of MBAER algorithm), which gave AOT close to 0.15 .

The key finding is that a deeper understanding of the retrieved AOT differences among the various sensors is needed in order to quantify climate forcing by natural and anthropogenic aerosols with greater confidence. Retrieval indeterminacies are likely part of the observed discrepancies, and their reduction will likely be aided by new missions incorporating spectral multi-angular polarimeters (see, e.g., Chowdhary et al., 2005). At the same time, issues of relative calibration, cloud screening, algorithm performance, surface reflectance assumptions, and aerosol models used in the retrievals from current sensors must be examined. Resolution of these differences will enable us to derive AOT over land and assign realistic uncertainties with much greater confidence.

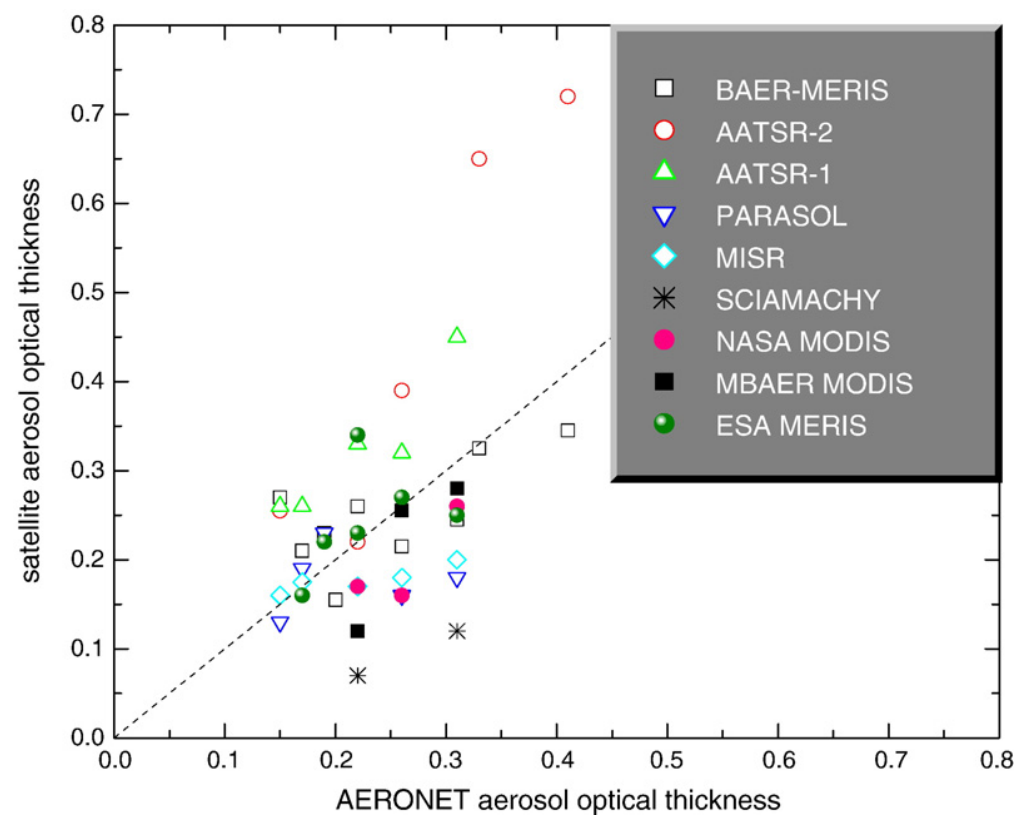

Fig. 16. The comparison of satellite and ground measurements of the aerosol optical thickness at the wavelength $0.55 \mu \mathrm{m}$. 


\section{Acknowledgements}

AERONET is acknowledged with respect to providing ground truth AOT data. The official ESA MERIS AOT product was provided by Philippe Garnesson (ACRI-ST) in the framework of PROMOTE. ESA and NASA are acknowledged for providing the satellite data. The authors thank their team members for the discussions and collaboration. The research of David Diner is carried out at the Jet Propulsion Laboratory, California Institute of Technology, under contract with the National Aeronautics and Space Administration. William Grey is funded by the UK Natural Environment Research Council through the Climate and Land-Surface Systems Interaction Centre. The research of K.-H. Lee was supported by the Korean Research Foundation Grant funded by the Korean Government (MOEHRD) (KRF2006-611-C00009). This work is dedicated to the memory of Yoram Kaufman, who made important contributions to the aerosol remote sensing over land. Centre National d'Etudes spatiales (France) is acknowledged for developing PARASOL and providing the data.

\section{References}

Abdou, W.A., Diner, D.J., Martonchik, J.V., Bruegge, C.J., Kahn, R.A., Gaitley, B.J., Crean, K.A., 2004. Comparison of coincident MISR and MODIS aerosol optical depths over land and ocean scenes containing AERONET sites. J. Geophys. Res. 110 (D10S07). doi:10.1029/2004JD004693.

Acarreta, J.R., Stammes, P., 2005. Calibration comparison between SCIAMACHY and MERIS onboard ENVISAT. IEEE Geosci. Remote Sens. Lett. 2, 31-35.

Ackerman, S.A., Strabala, K., Menzel, P., Frey, R., Moeller, C., Gumley, L., Baum, B., Seeman, S.W., Zhang, H., 1998. Discriminating clearsky from cloud with MODIS. Algorithm theoretical basis document (MOD35). J. Geophys. Res. 103, 32141-32157.

Bellouin, N., Boucher, O., Haywood, J., Reddy, M.S., 2005. Global estimate of aerosol direct radiative forcing from satellite measurements. Nature 438, 1138-1141.

Buchholtz, A., 1995. Rayleigh-scattering calculations for the terrestrial atmosphere. Appl. Opt. 34, 2765-2773.

Carboni, E., Thomas, G., Grainger, D., et al., 2006. GlobAEROSOL from Earth Observation - aerosol maps from (A)ATSR and SEVIRI, CDROM Proc. Atmos. Sci. Conference, Frascati, May 8-12.

Chowdhary, J., Cairns, B., Mishchenko, M.I., et al., 2005. Retrieval of aerosol scattering and absorption properties from photopolarimetric observations over the ocean during the CLAMS experiment. J. Atmos. Sci. 62, 1093-1117.

Chu, D.A., Kaufman, Y.J., Ichoku, C., Remer, L.A., Tanré, D., Holben, B.N., 2002. Validation of MODIS aerosol optical depth retrieval overland. Geophys. Res. Lett. 29. doi:10.1029/2001GL013205.

Chung, C.E., Ramanathan, V., Kim, D., Podgorny, I., 2005. Global anthropogenic aerosol direct forcing derived from satellite and ground-based observations. J. Geophys. Res. 110 (D24207). doi:10.1029/2005JD006356.
Cox, C., Munk, W., 1954. Measurement of the roughness of the sea surface from photographs of the sun's glitter. J. Opt. Soc. Am. 44, 838-850.

Deschamps, P.-Y., Bréon, F.-M., Leroy, M., Podaire, A., Bricaud, A., Buriez, J.-C., Seze, G., 1994. The POLDER mission: instrument characteristics and scientific objectives. IEEE Trans. Geosci. Remote Sens. 32, 598-615.

Deuze, J.L., Breon, F.M., Devaux, C., et al., 2001. Remote sensing of aerosols over land surfaces from POLDER-ADEOS-1 polarized measurements. J. Geophys. Res. 106, 4913-4926.

Diner, D.J., Martonchik, J., Kahn, R.A., et al., 2005. Using angular and spectral shape similarity constraints to improve MISR aerosol and surface retrievals over land. Remote Sens. Environ. 94, 155-171.

Di Nicolantonio, W., Cacciari, A., Scarpanti, S., Ballista, G., Morisi, E., Guzzi, R., 2006. SCIAMACHY TOA reflectance correction effects on aerosol optical depth retrieval. Proc. of the First Atmospheric Science Conference, ESA SP-628, 8-12 May 2006-ESA ESRIN.

Di Nicolantonio, W., Cacciari, A., Scarpanti, S., et al., submitted for publication. SCIAMACHY top of atmosphere reflectance correction effects on tropospheric aerosol retrieval, J. Geophys. Res.

Grainger, R.G., Lucas, J., Thomas, G., Ewen, G., 2004. Calculation of Mie derivatives. Appl. Opt. 43, 5386-5393.

Grey, W.M.F., North, P.R.J., Los, S.O., 2006a. Computationally efficient method for retrieving aerosol optical depth from ATSR-2 and AATSR data. Appl. Opt. 45, 2786-2795.

Grey, W.M.F., North, P.R.J., Los, S.O., Mitchell, R.M., 2006b. Aerosol optical depth and land surface reflectance from multi-angle AATSR measurements: global validation and inter-sensor comparisons. IEEE Trans. Geosci. Remote Sens. 44, 2184-2197.

Hess, M., Koepke, P., Schult, I., 1998. Optical properties of aerosol and clouds: the software Package OPAC. Bull. Am. Meteorol. Soc. 79 (5), 831-844.

Holben, B.N., Eck, T.F., Slutsker, I., et al., 1998. AERONET-a federated instrument network and data archive for aerosol characterization. Remote Sens. Environ. 66, 1-16.

Höller, R., Nagl, C., Haubold, H., Fanton D'Andon, O., Garnesson, P., 2005. Evaluation of MERIS aerosol products for national and regional air quality in Austria. ESA Proceedings, MERIS/(A) ATSR Workshop, ESRIN, Frascati, Italy.

Ichoku, C., Chu, D.A., Mattoo, S., Kaufman, Y.J., Remer, L.A., Tanré, D., Slutsker, I., Holben, B.N., 2002. A spatio-temporal approach for global validation and analysis of MODIS aerosol products. Geophys. Res. Lett. 29. doi:10.1029/2001GL013206.

Intergovernmental Panel on Climate Change, 2001. Climate Change. In: Houghton, J.T., Ding, Y., Griggs, D.J., et al. (Eds.), The Scientific Basis. Cambridge University Press, Cambridge.

Jin, Y., Schaaf, C.B., Woodcock, C.E., Gao, F., Li, X., Strahler, A.H., Lucht, W., Liang, S., 2003. Consistency of MODIS surface BRDF/ Albedo retrievals: 1. Algorithm performance. J. Geophys. Res. 108, 4158. doi:10.1029/2002JD002803.

Jourdan, O., Kokhanovsky, A.A., Burrows, J.P., 2007. Calibration of SCIAMACHY using AATSR top-of-atmosphere reflectance over a hurricane, IEEE Trans. Geosci. Remote Sens. Lett. 4, 8-12.

Kahn, R.A., Gaitley, B.J., Crean, K.A., Diner, D.J., Martonchik, J.V., Holben, B., 2005. MISR global aerosol optical depth validation based on two years of coincident AERONET observations. J. Geophys. Res. 110, D10S04. doi:10.1029/2004JD004706.

Karnieli, A., Kaufman, Y.J., Remer, L.A., Ward, A., 2001. AFRI Aerosol free vegetation index. Remote Sens. Environ. 77, 10-21.

Kaufman, Y.J., Tanré, D., 1992. Atmospherically resistant vegetation index (ARVI) for EOS MODIS. IEEE Trans. Geosci. Remote Sens. 30, 261-270. 
Kaufman, Y.J., Wald, A.E., Remer, L.A., et al., 1997. The MODIS $2.1 \mu \mathrm{m}$ channel - correlation with visible reflectance for use in remote sensing of aerosol. IEEE Trans. Geosci. Remote Sens. 35, 1286-1298.

Koelemeijer, R.B.A., Stammes, P., Hovenier, J.W., de Haan, J.F., 2001. A fast method for retrieval of cloud parameters using oxygen A band measurements from GOME. J. Geophys. Res. 106, 3475-3490.

Koelemeijer, R.B.A., de Haan, J.F., Stammes, P., 2003. A database of spectral surface reflectivity in the range 335-772 nm derived from 5.5 years of GOME observations. J. Geophys. Res. 108, D4070. doi:10.1029/2002JD002429.

Lee, K.H., Kim, J.E., Kim, Y.J., Kim, J., Hoyningen-Huene, W., 2005. Impact of the smoke aerosol from Russian forest fires on the atmospheric environment over Korea during May 2003. Atmos. Environ. 39, 85-99.

Lee, K.H., Kim, Y.J., von Hoyningen-Huene, W., Burrow, J.P., 2006. Influence of land surface effects on MODIS aerosol retrieval using the BAER method over Korea. Int. J. Remote Sens. 27, 2813-2830.

Levoni, C., Cattani, E., Cervino, M., Guzzi, R., Di Nicolantonio, W., 2001. Effectiveness of the MS method for computation of the intensity filed reflected by a multi-layer plane-parallel atmosphere. J. Quant. Spectrosc. Radiat. Transfer 69 (5), 635-650.

Martonchik, J.V., Diner, D.J., Crean, K.A., Bull, M.A., 2002. Regional aerosol retrieval results from MISR. IEEE Trans. Geosci. Remote Sens. 40, 1520-1531.

Martonchik, J.V., Diner, D.J., Kahn, R., Gaitley, B., Holben, B.N., 2004. Comparison of MISR and AERONET aerosol optical depths over desert sites. Geophys. Res. Lett. 31, L16102. doi:10.1029/ 2004GL019807.

Nadal, F., Bréon, F.-M., 1999. Parameterization of surface polarized reflectance derived from POLDER spaceborne measurements. IEEE Trans. Geosci. Remote Sens. 37, 1709-1718.

North, P.R.J., Briggs, S.A., Plummer, S.E., Settle, J.J., 1999. Retrieval of land surface bidirectional reflectance and aerosol opacity from ATSR-2 multi-angle imagery. IEEE Trans. Geosci. Remote Sens. $37,526-537$.

North, P.R.J., et al., 2002. Estimation of aerosol opacity and land surface bidirectional reflectance from ATSR-2 dual-angle imagery: operational method and validation. J. Geophys. Res. 107, D4149. doi:10.1029/2000JD000207.

Poulsen, C.A., Thomas, G.E., Siddans, R., Carboni, E., Grainger, R.G., in preparation: An optimal estimation aerosol algorithm using SEVIRI and AATSR. Part II: Validation.
Remer, L.A., Kaufman, Y.J., Tanre, D., et al., 2005. The MODIS aerosol algorithm, products and validation. J. Atmos. Sci. 62, 947-973.

Ricchiazzi, P., Yang, S., Gautier, C., Sowle, D., 1998. SBDART: A research and teaching software tool for plane-parallel radiative transfer in the Earth's atmosphere. Bull. Am. Meteorol. Soc. 79, 2101-2114.

Rodgers, C.D., 2000. Inverse Methods for Atmospheric Sounding: Theory and Practice. Series on Atmospheric Oceanic and Planetary Physics, vol. 2. World Scientific, Singapore.

Santer, R., Carrere, V., Dubuisson, P., Roger, J.C., 1999. Atmospheric corrections over land for MERIS. Int. J. Remote Sens. 20, $1819-1840$.

Santer, R., et al., 2000. Atmospheric product over land for MERIS level 2. MERIS Algorithm Theoretical Basis Document, ATBD 2.15, ESA

Stamnes, K., S-Chee Tsay, Wiscombe, W., Jayaweera, K., 1998. Numerically stable algorithm for discrete-ordinate-method radiative transfer in multiple scattering and emitting layered media. Appl. Opt. 27, 2502-2509.

Thomas, G.E., Dean, S.M., Carboni, E., Grainger, R.G., Poulsen, C.A., Siddans, R., Kerridge, B.J., 2005. ATSR-2/AATSR algorithm theoretical base document. ESA Globaerosol ATBD.

Thomas, G.E., Poulsen, C.A., Marsh, S.H., Watts, P.D., Siddans, R., Carboni, E., Grainger, R.G., in preparation. An optimal estimation aerosol algorithm using SEVIRI and AATSR. Part I: Algorithm description.

Veefkind, J.P., de Leeuw, G., Durkee, P.A., 1998. Retrieval of aerosol optical depth over land using two-angle view satellite radiometry during TARFOX. Geophys. Res. Lett. 25, 3135-3138.

Veefkind, J.P., de Leeuw, G., Stammes, P., Koelemeijer, R.B.A., 2000. Regional distribution of aerosol over land, derived from ATSR-2 and GOME. Remote Sens. Environ. 74, 386-577.

Vermote, E.F., Tanre, D., Deuze, J.L., Herman, M., Morcette, J.-J., 1997. Second simulation of the satellite signal in the solar spectrum, 6S: an overview. IEEE Trans. Geosci. Remote Sens. 35, 675-686.

von Hoyningen-Huene, W., Freitag, M., Burrows, J.B., 2003. Retrieval of aerosol optical thickness over land surfaces from top-of-atmosphere radiance. J. Geophys. Res. 108, 4260. doi:10.1029/2001JD002018.

Wiscombe, W., 1977. The Delta-M method: rapid yet accurate radiative flux calculations. J. Atmos. Sci. 34, 1408-1422.

Yu, H., Kaufman, Y.J., Chin, M., et al., 2005. A review of measurement-based assessment of aerosol direct radiative effect and forcing. Atmos. Chem. Phys. 5, 7647-7768. 